NASA/TM-2008-215453

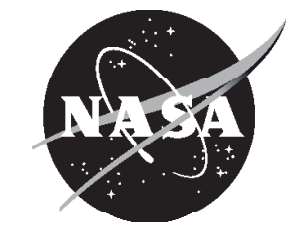

\title{
Current Methods for Modeling and Simulating Icing Effects on Aircraft Performance, Stability and Control
}

Thomas P. Ratvasky

Glenn Research Center, Cleveland, Ohio

Billy P. Barnhart

Bihrle Applied Research, Inc., Hampton, Virginia

Sam Lee

ASRC Aerospace Corporation, Cleveland, Ohio 


\section{NASA STI Program . . . in Profile}

Since its founding, NASA has been dedicated to the advancement of aeronautics and space science. The NASA Scientific and Technical Information (STI) program plays a key part in helping NASA maintain this important role.

The NASA STI Program operates under the auspices of the Agency Chief Information Officer. It collects, organizes, provides for archiving, and disseminates NASA's STI. The NASA STI program provides access to the NASA Aeronautics and Space Database and its public interface, the NASA Technical Reports Server, thus providing one of the largest collections of aeronautical and space science STI in the world. Results are published in both non-NASA channels and by NASA in the NASA STI Report Series, which includes the following report types:

- TECHNICAL PUBLICATION. Reports of completed research or a major significant phase of research that present the results of NASA programs and include extensive data or theoretical analysis. Includes compilations of significant scientific and technical data and information deemed to be of continuing reference value. NASA counterpart of peer-reviewed formal professional papers but has less stringent limitations on manuscript length and extent of graphic presentations.

- TECHNICAL MEMORANDUM. Scientific and technical findings that are preliminary or of specialized interest, e.g., quick release reports, working papers, and bibliographies that contain minimal annotation. Does not contain extensive analysis.

- CONTRACTOR REPORT. Scientific and technical findings by NASA-sponsored contractors and grantees.

- CONFERENCE PUBLICATION. Collected papers from scientific and technical conferences, symposia, seminars, or other meetings sponsored or cosponsored by NASA.

- SPECIAL PUBLICATION. Scientific, technical, or historical information from NASA programs, projects, and missions, often concerned with subjects having substantial public interest.

- TECHNICAL TRANSLATION. Englishlanguage translations of foreign scientific and technical material pertinent to NASA's mission.

Specialized services also include creating custom thesauri, building customized databases, organizing and publishing research results.

For more information about the NASA STI program, see the following:

- Access the NASA STI program home page at http://www.sti.nasa.gov

- E-mail your question via the Internet to help@ sti.nasa.gov

- Fax your question to the NASA STI Help Desk at 301-621-0134

- Telephone the NASA STI Help Desk at 301-621-0390

- Write to: NASA Center for AeroSpace Information (CASI) 7115 Standard Drive Hanover, MD 21076-1320 


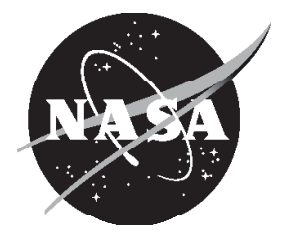

\section{Current Methods for Modeling and Simulating Icing Effects on Aircraft Performance, Stability and Control}

Thomas P. Ratvasky

Glenn Research Center, Cleveland, Ohio

Billy P. Barnhart

Bihrle Applied Research, Inc., Hampton, Virginia

Sam Lee

ASRC Aerospace Corporation, Cleveland, Ohio

Prepared for the

Atmospheric Flight Mechanics Conference and Exhibit

sponsored by the American Institute of Aeronautics and Astronautics

Honolulu, Hawaii, August 18-21, 2008

National Aeronautics and

Space Administration

Glenn Research Center

Cleveland, Ohio 44135 


\section{Acknowledgments}

The authors wish to thank Christine Belcastro for inviting us to prepare and present this report at the Aircraft Loss of Control I: Modeling and Simulation Session of the 2008 AIAA Aircraft Flight Mechanics Conference. Further thanks go to Tom Bond, Mark Potapczuk, Rich Ranaudo, Gene Addy, Andy Broeren, and the NASA Aviation Safety Program for their continued support and efforts during the icing effects studies described herein.

Trade names and trademarks are used in this report for identification only. Their usage does not constitute an official endorsement, either expressed or implied, by the National Aeronautics and Space Administration.

Level of Review: This material has been technically reviewed by technical management.

Available from

NASA Center for Aerospace Information 7115 Standard Drive

Hanover, MD 21076-1320
National Technical Information Service 5285 Port Royal Road Springfield, VA 22161

Available electronically at http://gltrs.grc.nasa.gov 


\title{
Current Methods for Modeling and Simulating Icing Effects on Aircraft Performance, Stability and Control
}

\author{
Thomas P. Ratvasky \\ National Aeronautics and Space Administration \\ Glenn Research Center \\ Cleveland, Ohio 44135 \\ Billy P. Barnhart \\ Bihrle Applied Research, Inc. \\ Hampton, Virginia 23666 \\ Sam Lee \\ ASRC Aerospace Corporation \\ Cleveland, Ohio 44135
}

\begin{abstract}
Icing alters the shape and surface characteristics of aircraft components, which results in altered aerodynamic forces and moments caused by air flow over those iced components. The typical effects of icing are increased drag, reduced stall angle of attack, and reduced maximum lift. In addition to the performance changes, icing can also affect control surface effectiveness, hinge moments, and damping. These effects result in altered aircraft stability and control and flying qualities. Over the past 80 years, methods have been developed to understand how icing affects performance, stability and control. Emphasis has been on wind tunnel testing of two-dimensional subscale airfoils with various ice shapes to understand their effect on the flow field and ultimately the aerodynamics. This research has led to wind tunnel testing of sub-scale complete aircraft models to identify the integrated effects of icing on the aircraft system in terms of performance, stability, and control. Data sets of this nature enable pilot in the loop simulations to be performed for pilot training, or engineering evaluation of system failure impacts or control system design.
\end{abstract}

\section{Nomenclature}

$\begin{array}{ll}\alpha, A o A & \text { angle of attack, deg } \\ \beta & \text { angle of sideslip, deg } \\ b & \text { wing span } \\ \delta_{a}, \delta_{e}, \delta_{r}, \delta_{f} & \text { control surface deflection: aileron, elevator, rudder, flap, deg } \\ C_{d}, C_{D} & \text { drag coefficient } \\ C_{h, \delta A} & \text { aileron hinge moment } \\ C_{l}, C_{L} & \text { lift coefficient } \\ C_{L, \delta A} & \text { aileron control effectiveness } \\ C_{N} & \text { normal force coefficient } \\ C_{m} & \text { pitching moment coefficient } \\ C_{m \alpha} & \text { pitching moment coefficient derivative with } A o A, \text { longitudinal stability } \\ \bar{c} & \text { chord length } \\ \text { CAST } & \text { Commercial Aviation Safety Team } \\ \text { CFD } & \text { computational fluid dynamics } \\ \text { ICEFTO } & \text { Ice Contamination Effects Flight Training Device } \\ \text { k/ } \bar{c} & \text { ratio of protuberance height to chord length }\end{array}$




$\begin{array}{ll}\text { IPS } & \text { ice protection system } \\ \text { LAMP } & \text { Bihrle Applied Research Large Amplitude Multi-Purpose wind tunnel } \\ \text { LWC } & \text { liquid water content } \\ \text { MVD } & \text { median volumetric diameter } \\ \text { Re } & \text { Reynolds number }\end{array}$

\section{Introduction}

Airframe icing has been a threat to aviation safety for nearly 80 years. Over that time, significant progress has been made to reduce the hazard through the design and implementation of ice protection systems, certification processes, and pilot training. The foundation of these advancements has been research to better understand the icing environment, the physics of the ice accretion process, and the degrading aerodynamic effects caused by ice. However, even with these advancements, icing-induced loss of control incidents and accidents have occurred and continue to occur on all classes of aircraftfrom general aviation airplanes (refs. 1 and 2) and business jets (refs. 3 and 4), to transport category aircraft (refs. 5 to 11). These events typically result from a combination of causal factors, but they usually precipitate from the altered aerodynamics caused by icing.

The continuing problem of icing has been recognized by many organizations including the National Transportation Safety Board (NTSB), the Commercial Aviation Safety Team (CAST), the Federal Aviation Administration (FAA), and the National Aeronautics and Space Administration (NASA). The NTSB has made numerous safety recommendations after icing related incidence and accidents, and has ranked icing among its "MOST WANTED Aviation Transportation Safety Improvements"1 since 1997. CAST, a consortium of industry and government organizations working to improve aviation safety, has developed interventions specific to icing. They have also specified that the implicit icing effects on flight envelope protection and high-fidelity simulators for upset recovery training are among their highest ranked intervention needs (ref. 12). The FAA and the NASA Aeronautics Research Mission Directorate have invested significant resources to support these safety recommendations, develop interventions, and to advance the state of knowledge on the icing atmosphere, the ice accretion process, and aerodynamic effects of icing.

The purpose of this paper is to review the methods currently available to model and simulate icing effects on performance, stability and control. The primary method to model icing effects utilize wind tunnel testing of two-dimensional and three-dimensional models to develop mathematical expressions or databases of aerodynamic forces and moments. Icing effects simulation utilizes these mathematical models or databases in conjunction with the equations of motion to explore the inter-relationship of various parameters and the modified flight envelope imposed by the iced aerodynamics. Icing effects modeling and simulation methods have varied maturity levels and limitations in terms of verification and validation. Recommendations are made to continue research in flight simulation modeling and real-time modeling to continue advancing the state-of-the-art.

\section{Airframe Icing-How it Forms}

In order to model and simulate the degraded aerodynamics that results from ice, one should understand the ice accretion process and the resulting ice characteristics since they drive the aerodynamic effects.

Ice forms on an airplane as it flies through clouds consisting of super-cooled liquid droplets (i.e., liquid water drops that are below $0{ }^{\circ} \mathrm{C}$ ). The liquid droplets impinge on the leading edge surfaces, exchange heat with the environment and aircraft surface, and change phase from liquid to ice. Initially, the ice forms as a thin, rough layer. Over time, the ice thickness increases and reshapes the leading edges

\footnotetext{
${ }^{1}$ http://www.ntsb.gov/Recs/mostwanted/aviation_issues.htm
} 
of all frontal surfaces. The rough, reshaped leading edges, in turn, degrade the aerodynamics of the airframe.

The ice accretion characteristics (size, shape, extent, roughness, and translucency) are related to the atmospheric environment parameters, the flight condition, the geometry of the aircraft component being iced, and the time in icing conditions. The icing cloud atmosphere has been defined into three primary parameters.

(1) Liquid Water Content (LWC): a measure of the amount of liquid water in a unit volume of space.

(2) Median Volumetric Diameter (MVD): a parameter to describe the characteristic size of the water droplet spectrum. MVD is a value for a given spectrum where half the volume of water is less than the MVD and half the volume of water is greater than the MVD.

(3) Static Temperature (Ts): the ambient air temperature.

The flight conditions consist of true airspeed, angle of attack, and altitude. Geometric parameters consist of the size of the leading edge radius, the chord length $(\bar{c})$, single or multielement wing, and straight or swept wing or tail. Each of the above parameters influences the ice accretion development. The result is a multitude of possible ice shapes.

To illustrate the resulting geometry change due to icing conditions, two ice shapes are shown in figure 1. They were accreted on a NACA 23012 airfoil model in the NASA Icing Research Tunnel (ref. 13). Figure 1(a) shows an example of a horn ice shape that forms at temperatures near freezing, where impinging water droplets can flow prior to freezing. Figure 1(b) shows an example of a streamwise ice shape. This type of ice forms at temperatures well below freezing where all of the impinging droplets freeze immediately on contact with the airfoil. Because these shapes are so different, they have very different effects on the aircraft aerodynamics.

To reduce the aerodynamic penalty of icing, ice protection systems (IPS) (ref. 14) are typically incorporated into airplanes to prevent or remove ice from critical flight components such as the wing and tail, engine nacelles and air intakes, propellers, as well as others. Ice protection systems that prevent ice from forming are typically called "anti-icing" systems, while those that remove ice are called "de-icing" systems. Anti-icing systems typically use heat from engine bleed air or electro-thermal heaters to evaporate water drops that impinge on the leading edge surfaces. De-icing systems de-bond ice that has already formed on the leading edge through a mechanical deformation of the surface (e.g., pneumatic deicing boots) or through intermittently heating the surface (e.g., electro-thermal heaters near the propeller root). The design of an IPS on any given airplane may use a combination of anti-icing and de-icing equipment. Some airplanes have bleed-air thermal anti-icing on the wings and engine nacelle leading edges only, leaving the tail surface completely unprotected. Others have pneumatic de-icing boots on the wing, and on the horizontal and vertical tails while having electro-thermal de-icing on propellers. Lastly, some have a combination of bleed-air thermal anti-icing on the wing and engine nacelle leading edges, pneumatic de-icing boots on the horizontal tail, and no ice protection on the vertical tail. There are other IPS designs as well, so the list could go on. In the end, the airframe manufacture determines the locations where ice protection is needed and what type of IPS is required to enable safe flight operations in icing conditions and meet certification requirements.

Airframe icing is a highly complex dynamic phenomenon. The ice that forms on an airplane is the result of a combination of icing cloud atmospheric parameters, flight conditions, airframe geometry, location and type of ice protection systems, and the time flown in icing conditions. Icing atmospheric conditions are not static, but change spatially and temporally. Similarly, flight conditions and airplane geometry change as the phase of flight changes from climb, cruise, descent, to approach and landing. Some ice protection systems do not remove all ice, but leave residual ice or inter-cycle ice on the protected surface. Some thermal IPS, may not fully evaporate the impinging water, and allow water to runback aft of the protected areas where it freezes to form an ice ridge. The amount of time in icing conditions also plays a significant roll as ice builds up on the unprotected surfaces such as unprotected tail, struts, radome, engine pylons, and flap hinge fairings. 

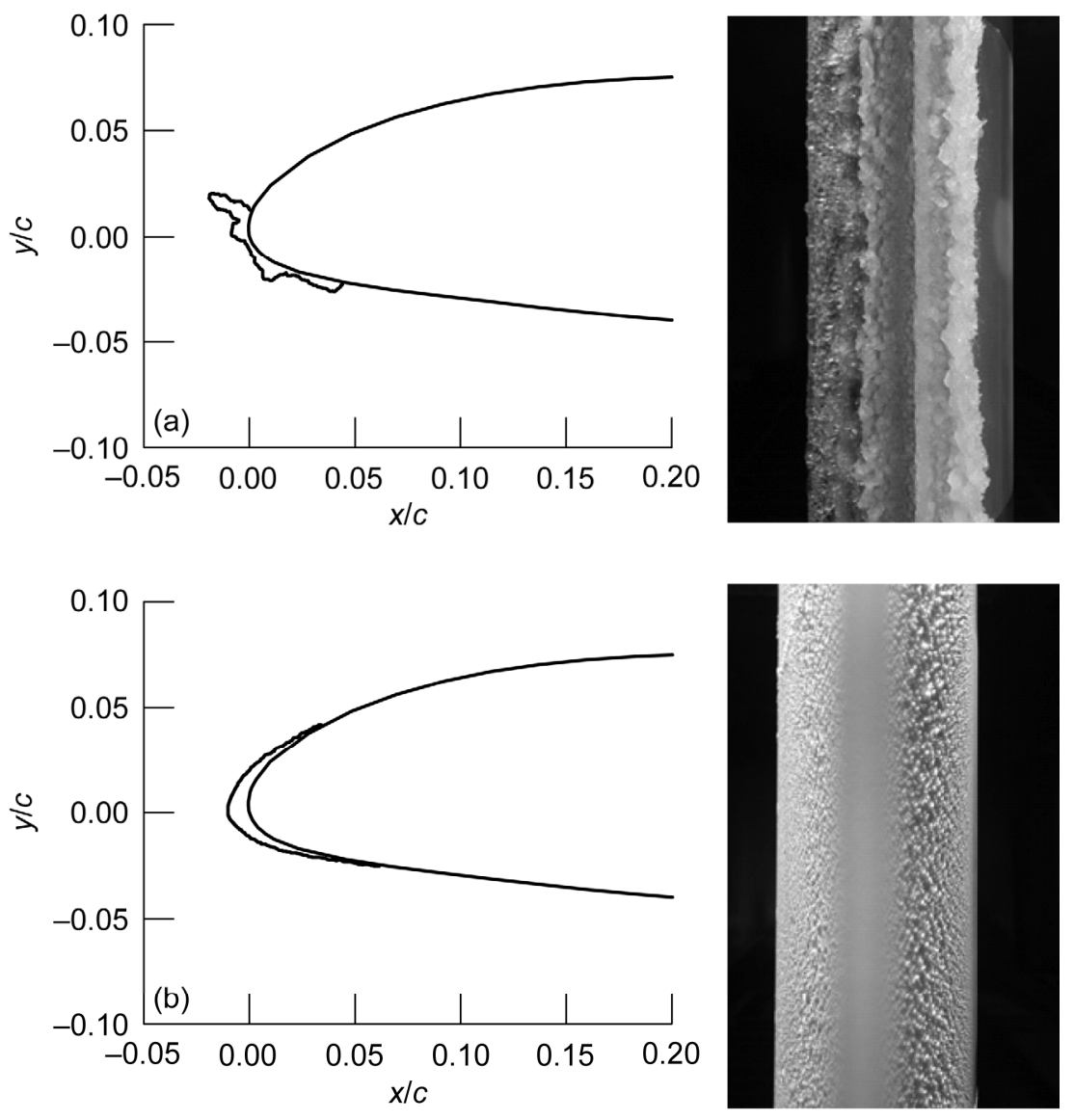

Figure 1.-lce shapes accreted at different condition in the NASA Icing Research Tunnel. (a) Ice accreted at temperature near freezing. (b) Ice accreted at temperature well below freezing.

Clearly, the inputs to icing formation are multidimensional and result in a wide range of potential ice shapes and ice characteristics. This presents a large challenge to accurately predict the entire range of possible effects on aircraft performance, stability and control, and handling. Over the past 80 years, many efforts have been undertaken to advance the understanding of ice accretion and the impact on aerodynamics. The next section briefly discusses some of these advancements.

\section{Modeling Icing Effects: Wind Tunnel Results From Two-Dimensional Wing Models}

The typical aerodynamic effects of ice on airfoils are increased drag, a reduced stall angle of attack and a reduced maximum lift. In addition to these primary parameters, icing affects the pitching moment and, if equipped with a control surface, the control effectiveness and hinge moment.

To understand and model these effects, research organizations have conducted numerous wind tunnel tests on a number of two-dimensional airfoil models and some three-dimensional wing and tail models. Recent iced aerodynamics simulation studies provide a significant body of knowledge examining the effects of ice accretion (size, shape, roughness, three-dimensionality) on drag increase, lift loss, and stall characteristics of a NACA 23012 airfoil at full-scale and sub-scale geometry and Reynolds numbers (ref. 13). Figure 2 illustrates the change in performance characteristics with different ice shapes. Drag increases are observed at the initial onset of icing (roughness) and increases as the ice takes shape and continues to grow in size. Drag increases are observable at all angles of attack. Ice affects lift mostly at 

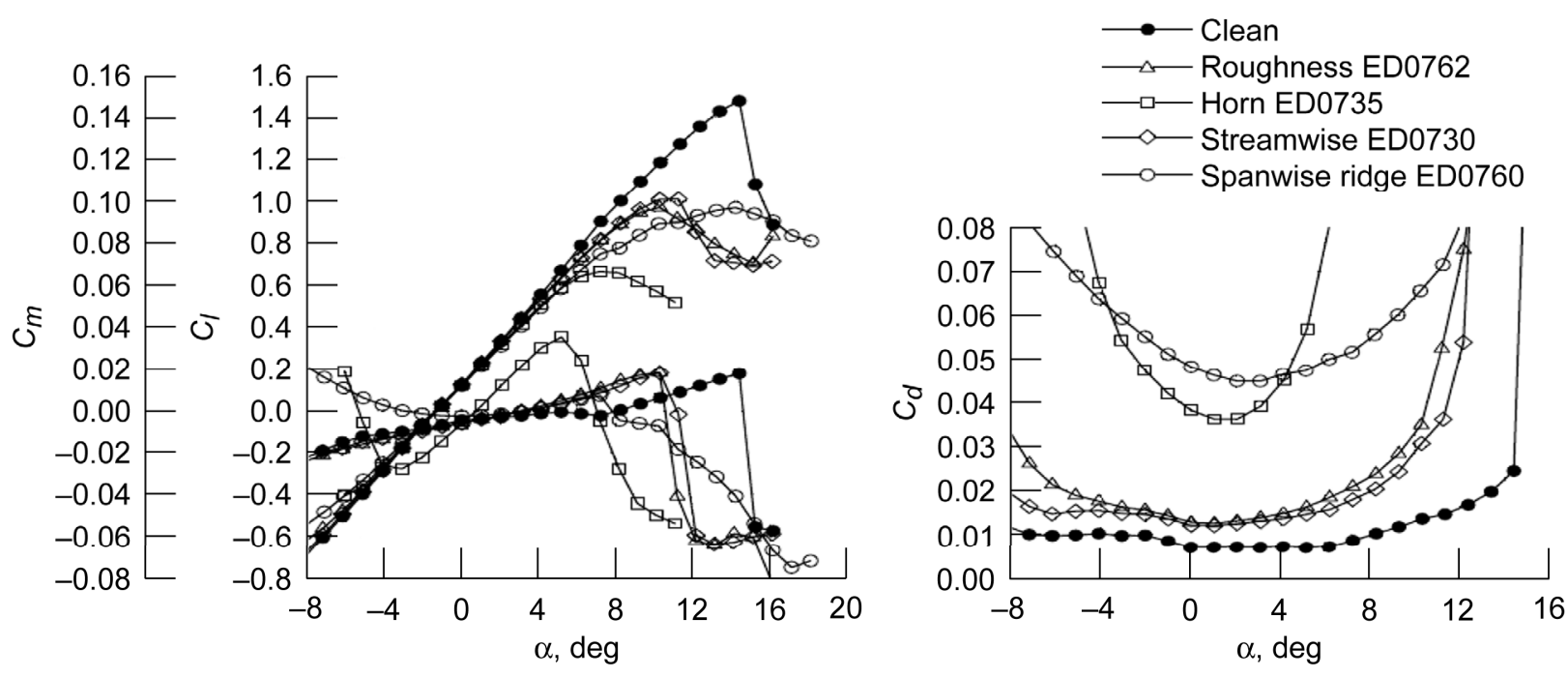

Figure 2.-Aerodynamic performance comparison for NACA 23012 model with casting simulations (ref. 13).
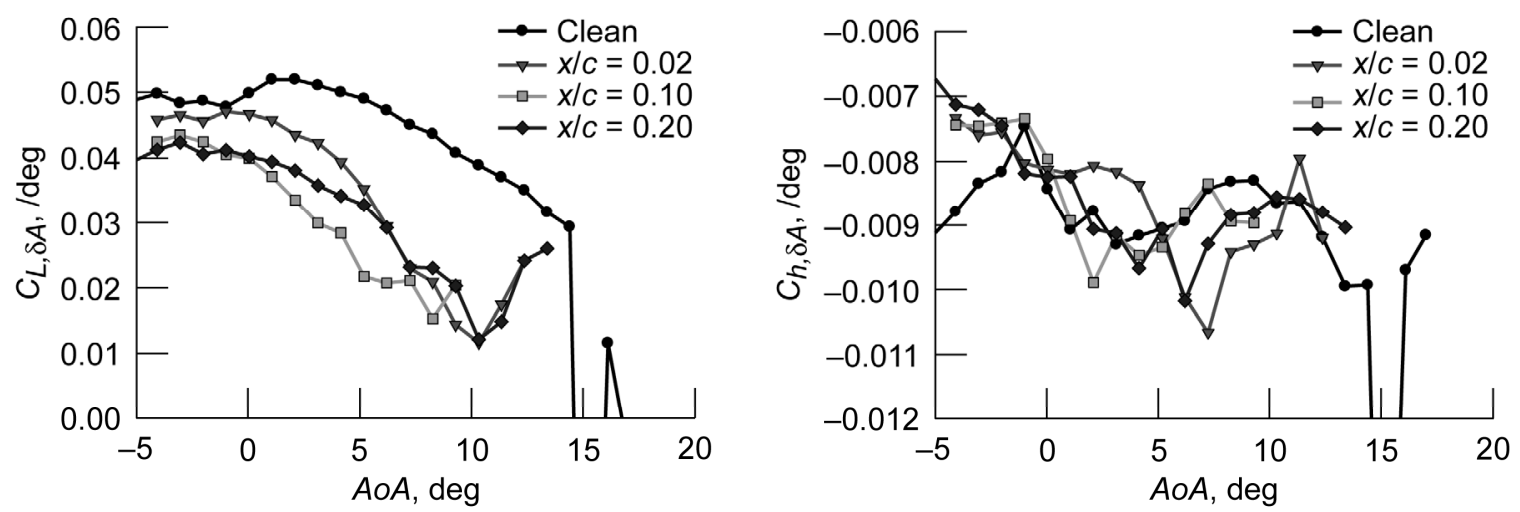

Figure 3.-Aileron effectiveness and hinge moment on NACA 23012 with simulated ice shapes at various chordwise locations.

higher angles of attack where early stall occurs. For roughness, this is due to early flow separation caused by loss of boundary layer momentum. For larger ice shapes, early stall occurs because the separation bubble that forms aft of the ice shape cannot reattach to the airfoil. Prior to this new stall point, there are shifts in the lift curve slope and the stall break, and post stall behavior is clearly affected by the ice. The pitching moment is also affected due to the altered pressure distribution over the airfoil, and a pitch up tendency occurs at significantly lower angles of attack compared to the clean (no ice) baseline.

Ice accretions have also degraded control surface effectiveness and increased the hinge moment loads on two-dimensional airfoil models. Figure 3 shows the effect of a simulated ice shape (in this case forward facing quarter round, $k / c=0.0139$ at various chordwise locations) on aileron effectiveness $\left(C_{L, \delta A}\right)$ and hinge moment $\left(C_{h, \delta A}\right)$. The first plot shows the rate of change in lift coefficient with change in aileron deflection, and the second plot shows the rate of change in hinge moment with change in aileron deflection. On the clean airfoil, the $C_{L, \delta A}$ value remained relatively constant from $A o A=-5^{\circ}$ to $5^{\circ}$. As the angle of attack was increased from this point, there was a gradual, almost linear reduction in aileron effectiveness to $A o A=14^{\circ}$ where the airfoil stalled. At stall, there was a sudden reduction in aileron effectiveness, where $C_{L, \delta A}$ became negative, meaning that deflecting the aileron trailing edge down at this angle of attack decreased lift. All three ice shape locations $(x / c=0.02,0.10$, and 0.20$)$ showed reduced aileron effectiveness at $A o A=0^{\circ}$, when compared with the clean airfoil. However, the reductions were greater when the ice shape was located at $x / c=0.10$ and 0.20 than when it was located at $x / c=0.02$. For 
all three iced cases, the aileron effectiveness started to decrease at lower angle of attack than the clean model. However, the rate at which it decreased varied with ice shape location. The hinge moment data did not show any noticeable trend in the rate of change in hinge moment with aileron deflection. The $C_{h, \delta A}$ values did not appear to vary significantly with change in angle of attack. Also, the presence of ice shapes did not appear to have altered the $C_{h, \delta A}$ values significantly either.

Experimental efforts such as these have enabled a comprehensive understanding of the basic flow physics associated with various ice accretions and helped identify the major aerodynamic penalties associated with the particular ice accretion studied. Bragg, Broeren, and Blumenthal (ref. 15) provided an in-depth analysis of flow fields caused by ice geometries categorized as roughness, horn ice, streamwise ice, and spanwise ridge ice. Studies such as these have been and continue to be critical in developing and validating computational fluid dynamics (CFD) tools to predict iced airfoil and eventually iced airplane aerodynamic characteristics. These studies are also beneficial in defining ice shapes characteristics that are critical to specific aerodynamic parameters. However, to understand the interaction of iced wings and tails for various ice shapes on airplane flight dynamics, a different approach and test methods need to be employed.

\section{Modeling Icing Effects: Wind Tunnel Results From Sub-Scale, Complete Airplane Models}

When considering the aerodynamic effects of ice on an airplane configuration, the effects found on two-dimensional airfoils apply, but are expanded upon. In this case, the effects of drag on the airfoils are not isolated, but couple into the pitching moment of the airplane. The lift degradation on the horizontal tail also couples into the airplane pitching moment in a static sense, but also a dynamic sense by reducing pitch damping. Lift degradation on the wing can affect longitudinal stability and roll damping. Adding the consequence of reduced control surface effectiveness can lead to an aircraft with substantially degraded stability and control and handling qualities.

These coupling effects are dependent on the airplane design, and airplane manufacturers are required to demonstrate safe flying characteristics with potential ice accretions that may occur in both normal operation and failure of the ice protection system. It is becoming common practice for manufacturers to perform wind tunnel tests on sub-scale models (component and complete airplane) with artificial ice shapes to gain insight into the aerodynamic penalties of icing.

To manage the wide range of possible ice shapes as described in section II, the ice shapes tested are defined based on flight scenarios, but the onus is on the manufacturer to define the most critical ice shape for the given scenario. The work that has been and continues to be performed in aerodynamic studies such as reference 15 helps identify the critical ice shape features and verify applicability of data from sub-scale testing. In practice, the ice shapes now commonly tested are (1) Ice Roughness [indicative of a delayed IPS activation or residual/inter-cycle ice], (2) Runback Ice [ice that forms aft of thermal IPS]; (3) Failure Ice [ice that forms on the IPS after a failure - typically large horn ice]; and (4) Holding Ice [ice that forms on unprotected surfaces during a 45 min hold - typically large horn ice].

Two test methods have been used to collect data on sub-scale, complete airplane models with ice shapes. These are static testing and static and dynamic testing. Each of these will be discussed in the following sub-sections.

\section{A. Static Testing of Sub-Scale, Complete Airplane Models}

Static testing produces databases of airplane force and moment coefficients for static conditions

$\left(\alpha, \beta, \delta_{\text {control surface, }}\right.$ ice case). These databases provide valuable insights into the effects that ice has on the airplane stability and control. Two examples of this type of modeling are provided to demonstrate this.

Prompted by icing related incidents, Kelly Johnson investigated the effects of ice on performance, stability and control on the Lockheed Electra (ref. 16). He found through wind tunnel tests using artificial 
ice shapes with a scaled model (fig. 4) that maximum lift was reduced by 32 percent, drag was increased by 47 percent, stall angle of attack was reduced by $4^{\circ}$, and aileron control effectiveness was reduced by 36 percent. Figure 5 shows the effect of icing on roll control. The results were obtain at $\operatorname{Re}=1.6$ million. These data clearly show the dramatic reduction in stability and control when the Electra was iced up.

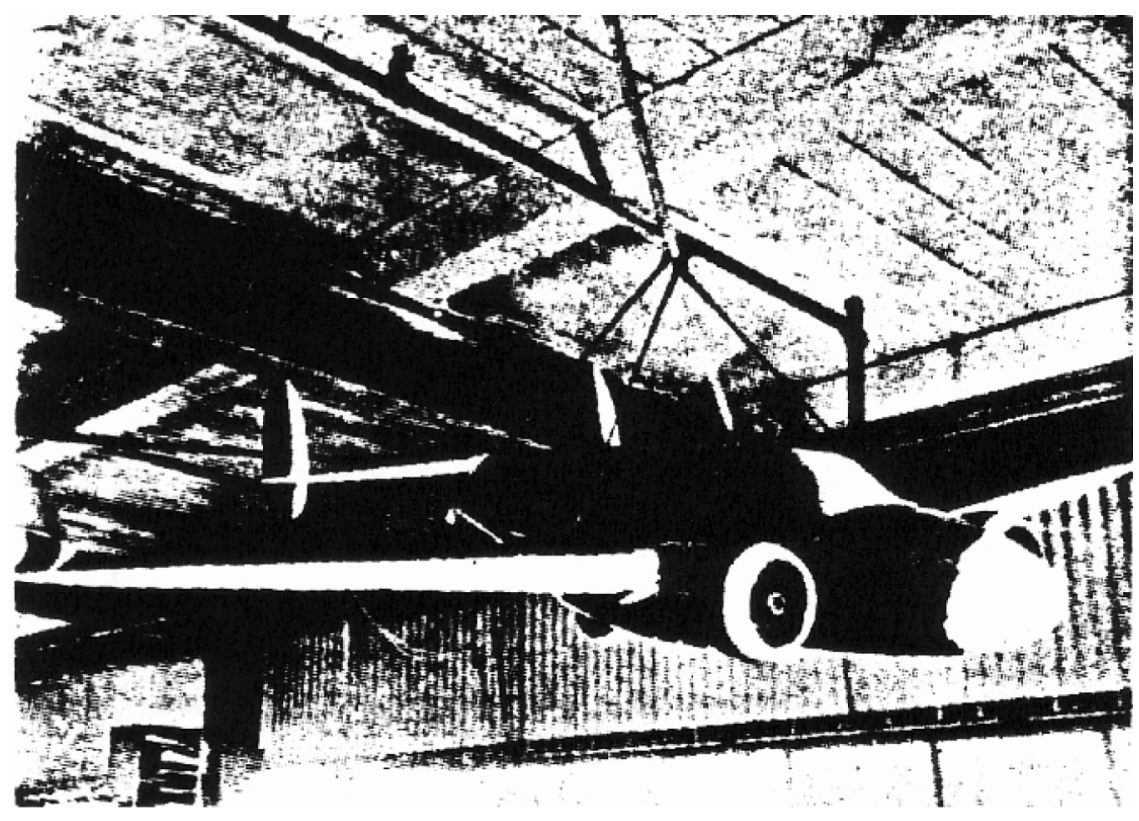

Figure 4.-Subscale Lockheed Electra with artificial ice shapes.

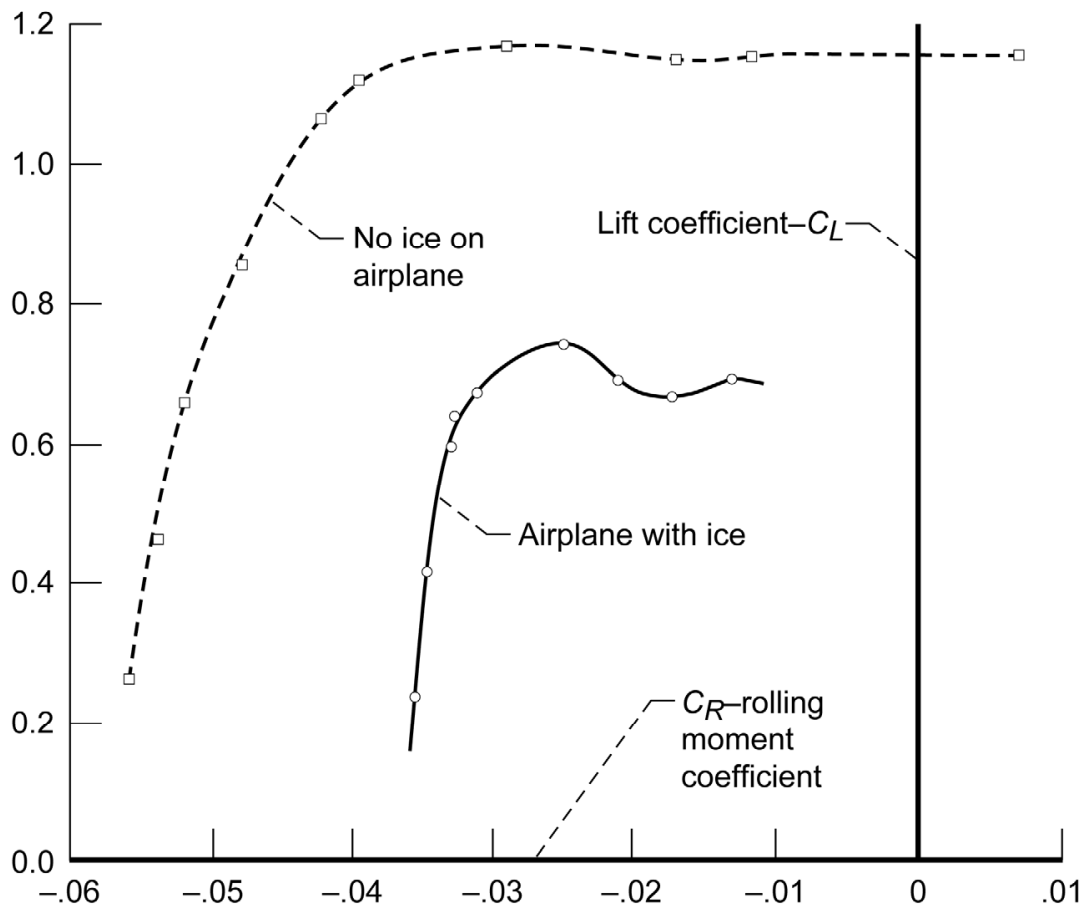

Figure 5.-Effect of ice on aileron control-full aileron deflection (ref. 16). 


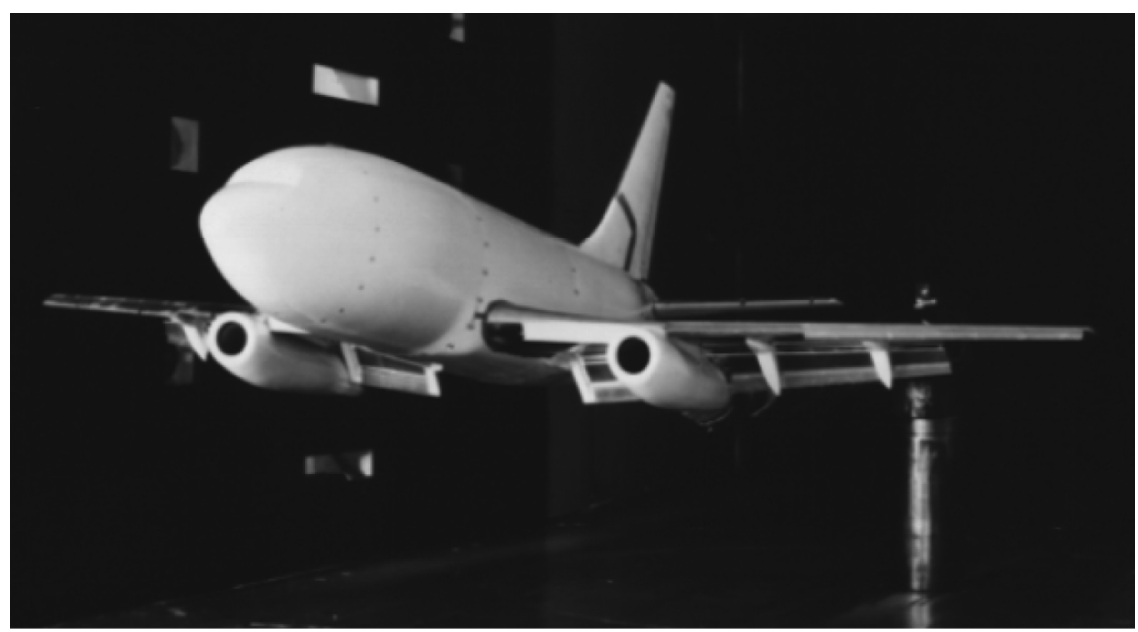

Figure 6.-NASA Langley 1/8-scale twin engine subsonic transport model.

More recently, NASA conducted a static wind tunnel test on a twin-engine short-haul transport to measure icing effects on performance and stability (ref. 17) at the NASA Langley Research Center (LaRC) 14 by $22 \mathrm{ft}$ wind tunnel. These tests were conducted on a $1 / 8$-scale model (fig. 6) at $\mathrm{Re}=$ 1.7 million. Representative results from this test are shown in figure 7 . In this case, the ice shapes on the wings reduced stall angle of attack by about $5^{\circ}$ and lowered maximum lift coefficient $\left(C_{L \max }\right)$ by approximately 16 percent compared to the clean data at the test Reynolds number. The difference between the iced configuration and the No-Ice configuration at flight Reynolds number is expected to be greater due to increase in $C_{L \max }$ for the No-Ice configuration. A positive shift in the pitching moment occurred with the ice cases, but longitudinal stability $\left(C_{m \alpha}\right)$ was relatively the same as the No-Ice case until the $A o A$ reached about $8^{\circ}$ where stall occurred and the aircraft became longitudinally unstable. No data were acquired with control surface deflections other than flaps in this wind tunnel test, so control effectiveness with the ice shapes could not be evaluated.

\section{B. Static and Dynamic Testing of Sub-Scale, Complete Airplane Models}

Although static testing provides insights into the effect ice has on stability and control, it does not address the effects on dynamic motion. To better understand and model the full range of an iced aircraft flight dynamics, data from forced oscillation and rotary balance tests need to be gathered.

To that end, static and dynamic wind tunnel tests were conducted under various projects on scaled DeHavilland DHC-6 Twin Otter, Cessna business jet (ref. 18), and Lockheed S-3B Viking models at the Bihrle Applied Research Large Amplitude Multi-Purpose (LAMP) facility in Neuburg, Germany (fig. 8). The scale of the models were $6.5,8.3$, and 6.5 percent and were tested at $\operatorname{Re}=0.13,0.15$, and 0.20 million respectively.

The primary purpose of these research efforts was to understand the effect of airframe icing on flight dynamics. This was accomplished through the creation of flight simulation models that utilized the aerodynamic databases derived from wind-tunnel tests results. This process was used to explore the utility of iced flight simulation in pilot training applications using the Twin Otter aircraft. Simulation models were developed for the No-Ice (clean) and two IPS failure ice-shape configurations. The successful implementation of this approach led to a similar effort using a Cessna business jet. In this case, four configurations were considered: No-Ice (clean), ice roughness, wing IPS failure ice and wing runback ice. Lastly, as NASA Glenn is modifying a Lockheed S-3B Viking for icing flight research, there is a need to understand the impact of potential ice accretions on its flight dynamics. In this case, data were acquired for the No-Ice baseline configuration, and icing configurations consisting of large horn ice shapes on the wing and tail leading edges to represent a hold in icing conditions, and spanwise ridge shapes aft of the thermal IPS on the wing and horizontal tail to represent runback ice. 

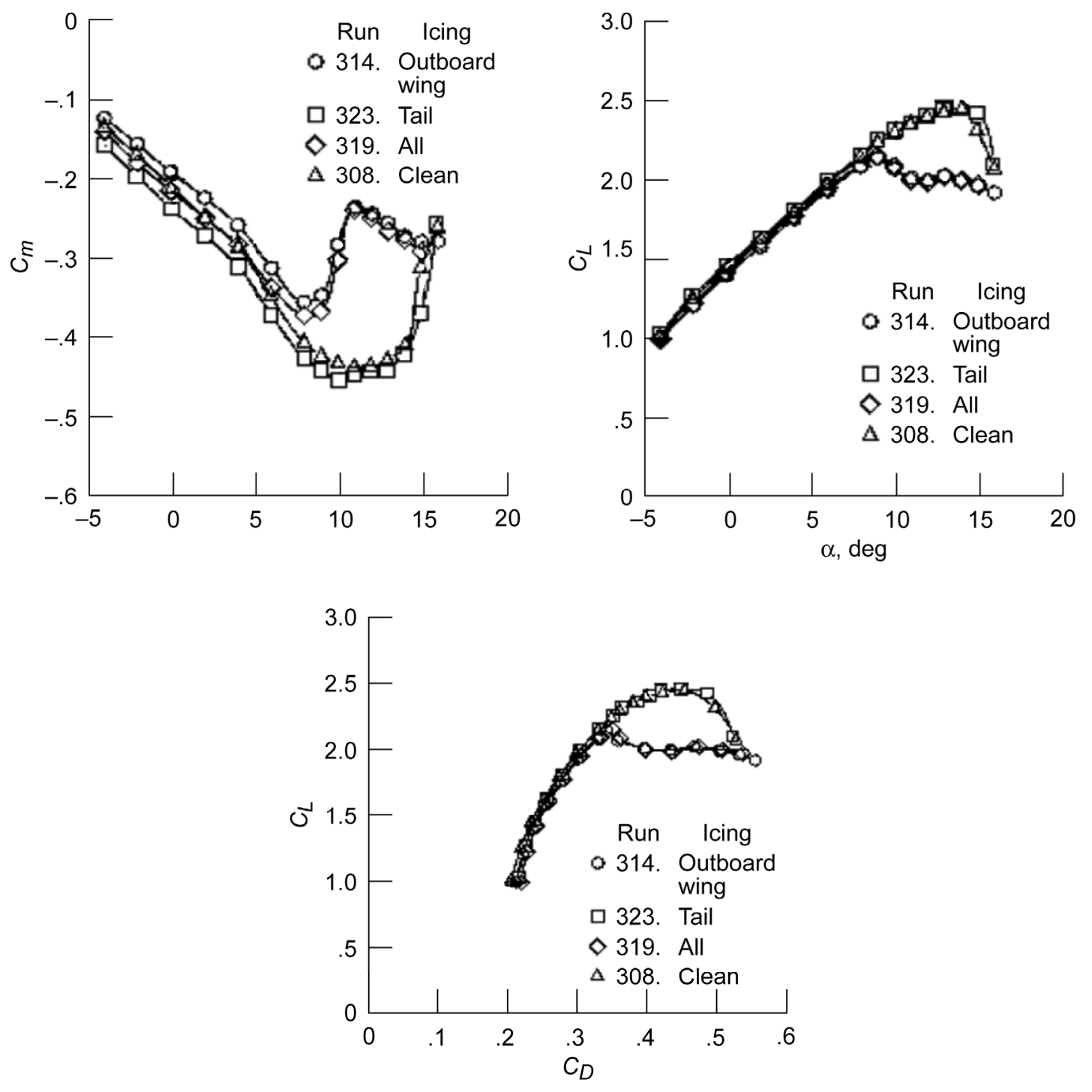

Figure 7.-Effects of ice on longitudinal aerodynamics of twin engine transport, $\delta_{f}=40^{\circ}$ (ref. 17).
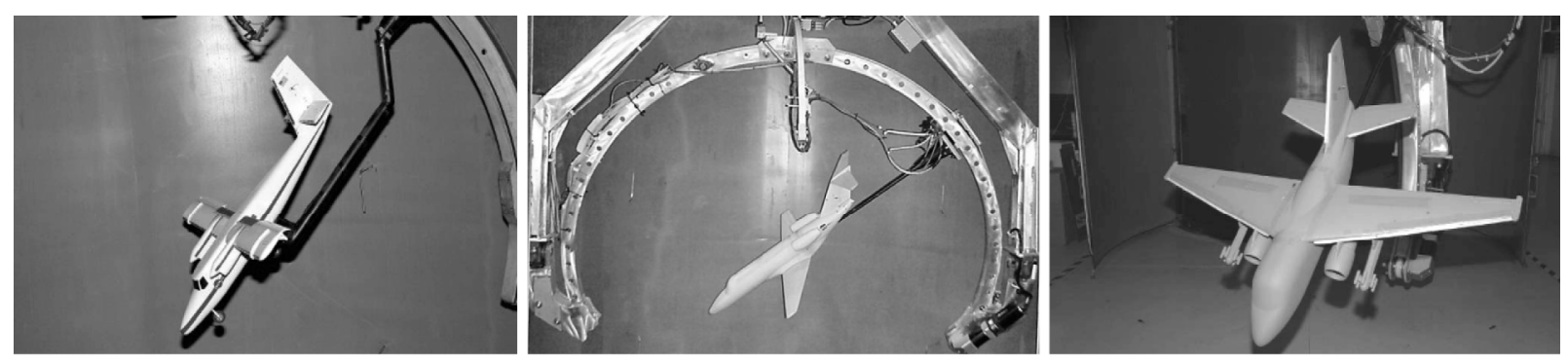

Figure 8.-Scale models of DHC-6 Twin Otter, Cessna business jet, and S-3B Viking. 


\section{Challenges Associated With Sub-Scale, Complete Airplane Model Testing}

The geometric scale of these models and the associated Reynolds numbers required the development of methods to account for: (1) the premature stalling characteristics typical of low Re, and (2) ice accretion scaling to represent full scale iced aerodynamics. In order to develop flight simulation models that are representative of full-scale flight characteristics from the low Re wind tunnel data, the "clean" No-Ice wind tunnel data are projected out along a trend line to the angle of attack where stall is anticipated at flight Reynolds numbers. This angle of attack can be determined from other sources such as high Reynolds number wind tunnel data and flight tests. This method of data extension is shown in figure 9 for the Twin Otter and figure 10 for the Cessna business jet. Another challenge with this type of wind tunnel data is the reduced effectiveness of flaps for high lift (fig. 9). As flap angle increased, the change in lift associated with that flap deflection was not as great as seen in flight. In this case, corrections were made based on flight data.

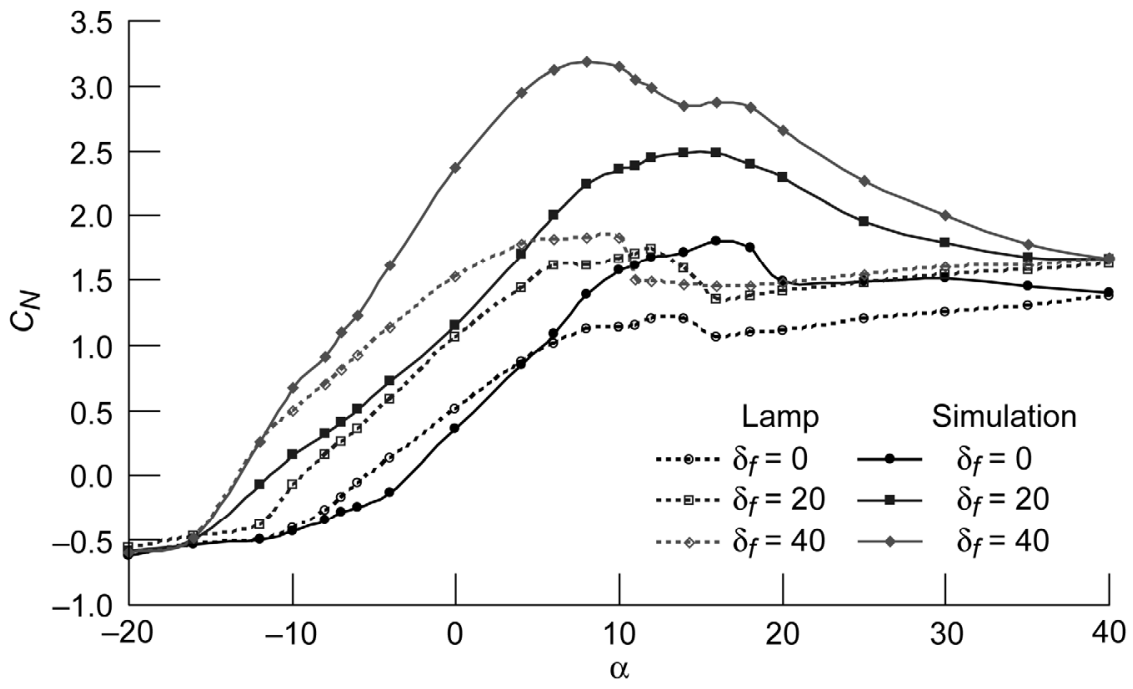

Figure 9.-Comparison of Twin Otter No-Ice wind tunnel normal force coefficient data with simulation model values for flight $\mathrm{Re}$.
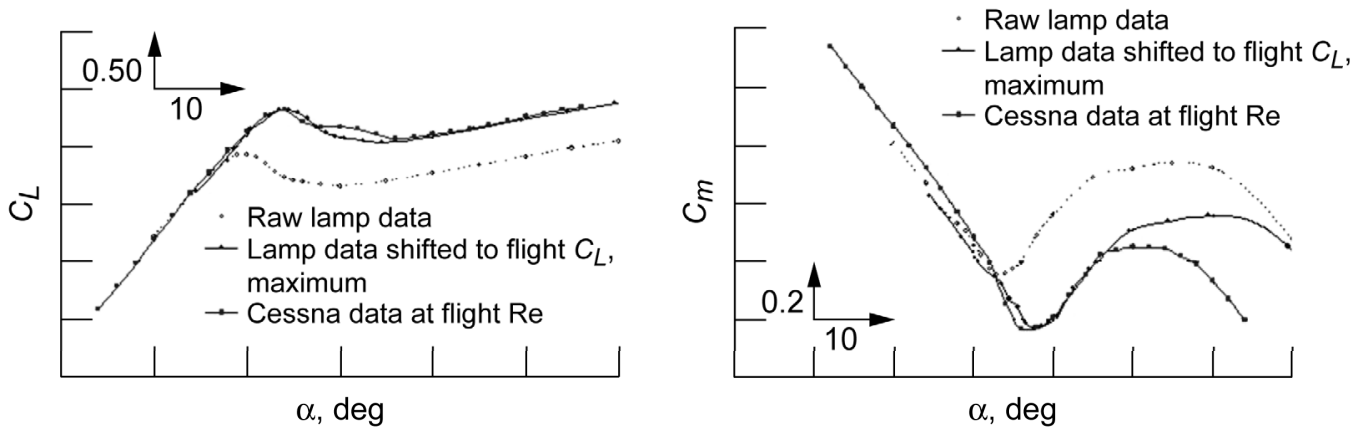

Figure 10.-Comparison of business jet No-Ice $C_{L}$ and $C_{m}$ wind-tunnel data with simulation model values for flight $\mathrm{Re}$. 


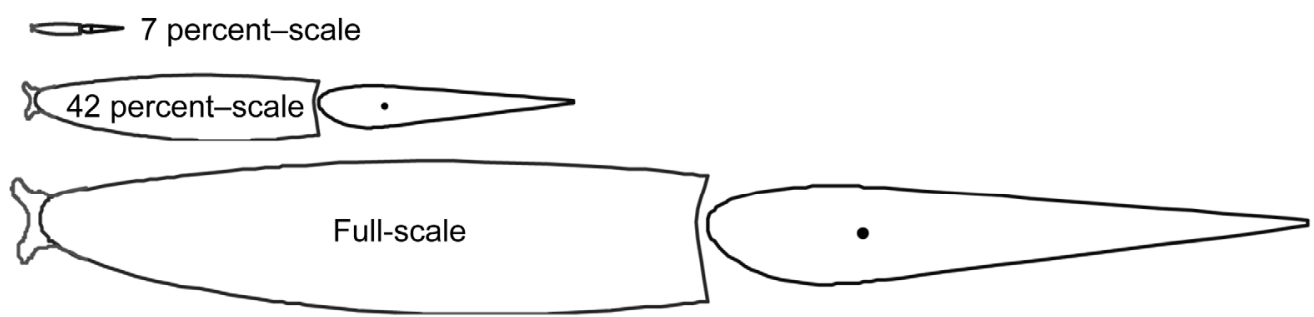

Figure 11.-Depiction of Twin Otter horizontal tail at various scales.

The small geometric scale of the complete airplane test articles, required methods for defining the size and position of artificial ice shapes to represent full scale aerodynamics. Although research on subscale two-dimensional airfoils with large ice shapes has shown iced aerodynamics to be relatively insensitive to Re effects (ref. 15), these complete aircraft model tests were conducted at much lower Re, and further research was warranted. To that end, a series of wind tunnel tests on full scale, mid-scale and small-scale test articles were conducted. The small-scale test articles were representative of the sub-scale complete aircraft models. For the Twin Otter, this consisted of testing a full scale, a 42 percent-scale and a 7 percent-scale horizontal tail (fig. 11) to identify the size and position of the artificial ice for the 6.5 percent-scale Twin Otter model (ref. 19). The full-scale ice shape for the wing and horizontal and vertical tail are shown in figure 12.

For the Cessna business jet, these tests used a full-scale, a 41.7 percent-scale and an 8.3 percent-scale wing panel model (fig. 13) to identify the artificial ice for the 8.3 percent-scale business jet model (ref. 20). The full-scale ice shapes that were tested are shown in figure 14.

These tests provided valuable insight into the aerodynamic scaling relationships for artificial ice shapes. For example, the failure IPS ice shapes could be geometrically scaled to obtain representative aerodynamics with the subscale model at low Re conditions. The roughness and runback ice cases for the Cessna business jet proved to be greater challenges. For these ice shapes, geometric simulation did not produce acceptable results because the full-scale $C_{L \max }$ with ice shapes were greater than the sub-scale No-Ice baseline $C_{L \max }$. This led to determining the size and position of artificial ice on the subscale model that had similar offsets observed in the full scale tests. Those results were then projected to the flight $\operatorname{Re}$ condition similar to the No-Ice baseline simulation models.

\section{Aerodynamic Model Results}

The aerodynamic scaling tests provided confidence that the measurements made in the LAMP facility could be utilized for modeling full scale flight dynamics. The data acquired at the LAMP consisted of forces and moments along all three axes for static conditions $\left(\alpha, \beta, \delta_{a}, \delta_{e}, \delta_{r}, \delta_{f}\right)$, forced oscillations in roll, pitch, and yaw axes, and steady rotation about the wind vector. These data were acquired for the NoIce baseline and for the iced configurations The No-Ice baseline data were shifted to a full scale Re stall $A o A$ as described above. To illustrate key effects that ice had on the aerodynamic characteristics, select aerodynamic model results from the Twin Otter effort (refs. 21 and 22) are presented.

\section{a. Normal Force}

The normal force coefficients were measured over a wide range of angles of attack, sideslip angles, elevator deflections, rotational velocities, and pitch rates during forced oscillations. Data from these measurements were analyzed to determine the model structural dependencies and to insure the preservation of all nonlinear effects. The initial definition of the basic airframe was built from the most significant functional dependencies. For the Twin Otter these were: angle of attack, angle of sideslip and flap deflection. Incremental coefficient data tables were then generated to provide the effects of control deflections, dynamic damping, and power effects. The normal force coefficent can be represented by equation (1). The $C_{N_{\mathrm{BASIC}}}$ lookup table is based on static inputs of $\alpha, \beta, \delta_{f}$. The $\Delta \mathrm{C}_{\mathrm{N}_{\mathrm{ROT}}}$ lookup table of 

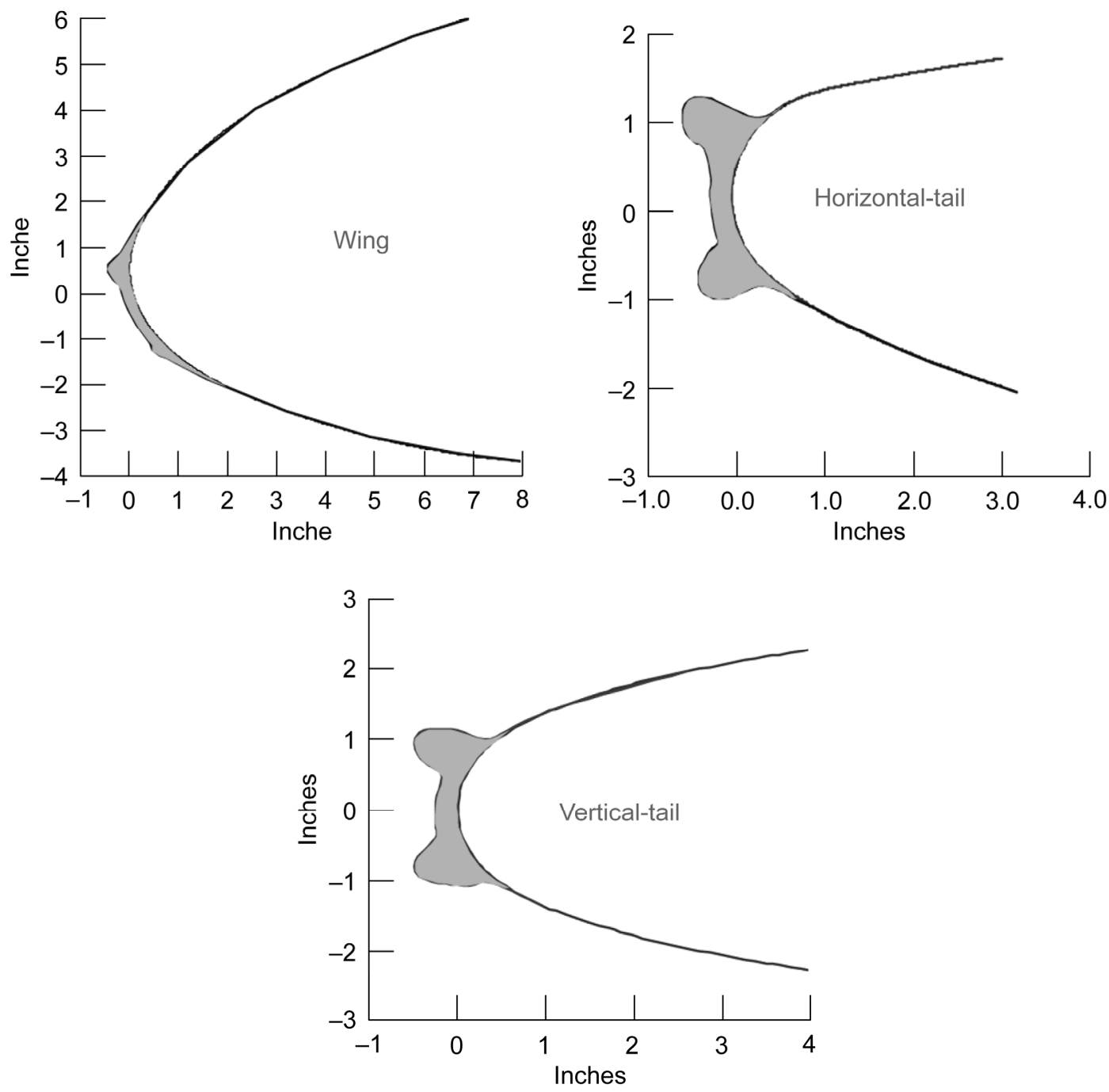

Figure 12.-Full-scale ice shape profiles for Twin Otter wing, horizontal-tail and vertical-tail.
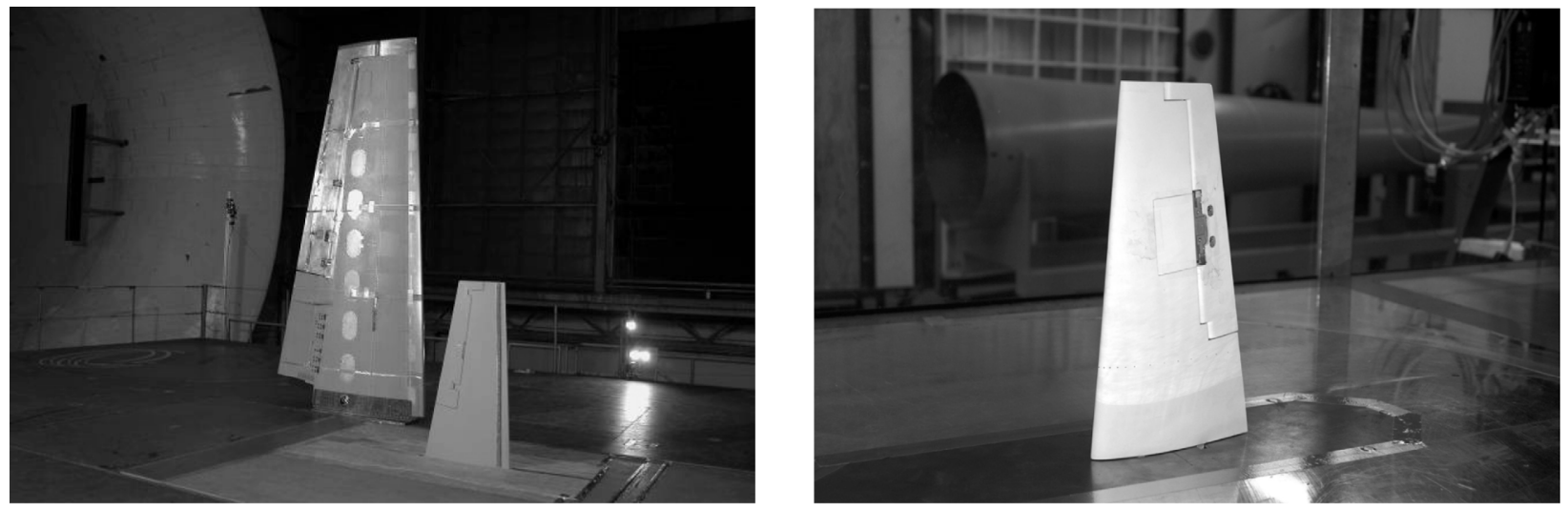

Figure 13.-Full-scale, 41.7 percent-scale, and 8.3 percent-scale business jet wing panel models. 


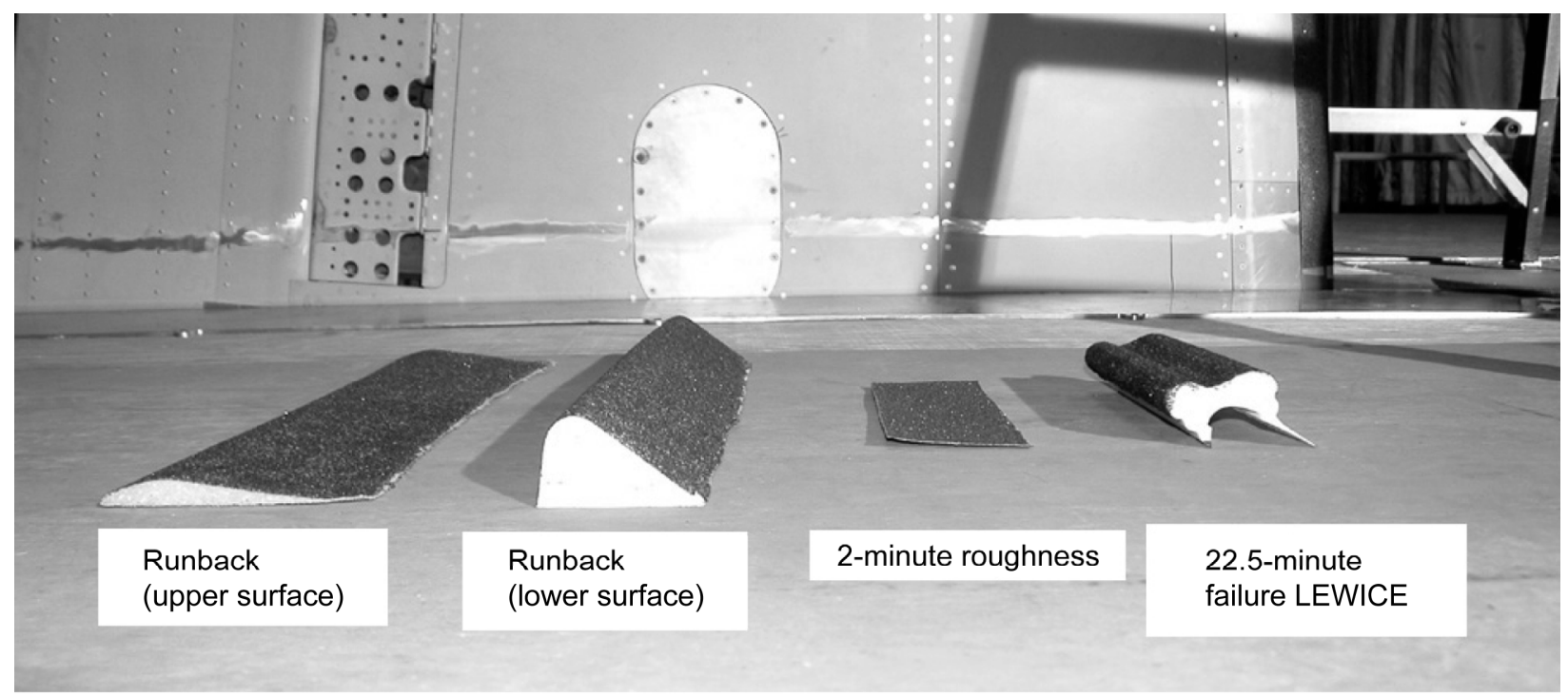

Figure 14.--Ice shapes tested on full-scale business jet wing panel.

increments of $C_{N}$ is based on inputs of $\alpha, \Omega b / 2 \mathrm{~V} \times \mathrm{SGN}(\beta),|\beta|, \delta_{f}$. The $\Delta C_{N_{\mathrm{DE}}}$ lookup table of increments of $C_{N}$ is based on static inputs $\alpha, \delta_{e}, \delta_{f}$. Lastly, the $\Delta C_{N_{\mathrm{Q}}}$ lookup table of increments of $C_{N}$ is based on inputs $\alpha, q \bar{c} / 2 \mathrm{~V}, \delta_{f}$. The result from each of these lookup tables is added to arrive at the total normal force coefficient.

Normal force coefficient model for No-Ice baseline.

$$
\begin{aligned}
C_{N_{\text {TOtALCLEAN }}} & =C_{N_{\text {BASIC }}}\left(\alpha, \beta, \delta_{f}\right)+\Delta C_{N_{\mathrm{ROT}}}\left(\alpha, \Omega b / 2 \mathrm{~V} * \operatorname{SGN}(\beta), \beta \mid, \delta_{f}\right) \\
& +\Delta C_{N_{\mathrm{DE}}}\left(\alpha, \delta_{e}, \delta_{f}\right)+\Delta C_{N_{\mathrm{Q}}}\left(\alpha, q \bar{c} / 2 \mathrm{~V}, \delta_{f}\right)
\end{aligned}
$$

The differences in the No-Ice and ICE02 (IPS failure ice on wing, horizontal and vertical tail) data sets drove the modeling effort to create separate databases for each configuration. Equation (2) shows that the model structure for ICE02 is the same as the No-Ice, but the values within the tables are different.

Normal force coefficient model for All-Iced (ICE02).

$$
\begin{aligned}
C_{N_{\mathrm{TOTAL} I \mathrm{ICE} 02}} & =C_{N_{\mathrm{BASE} 12}}\left(\alpha, \beta, \delta_{f}\right)+\Delta C_{N_{\mathrm{ROT} 12}}\left(\alpha, \Omega b / 2 \mathrm{~V} * \operatorname{SGN}(\beta),|\beta|, \delta_{f}\right) \\
& +\Delta C_{N_{\mathrm{DE} 12}}\left(\alpha, \delta_{e}, \delta_{f}\right)+\Delta C_{N_{Q 12}}\left(\alpha, q \bar{c} / 2 \mathrm{~V}, \delta_{f}\right)
\end{aligned}
$$

As an example of the $C_{N_{\text {BASIC }}}$ lookup tables, the normal force coefficient data for the Twin Otter with flaps at $0^{\circ}, 20^{\circ}$, and $40^{\circ}$ are presented in figure 15 for the No-Ice baseline and the ICE02 configurations. Comparing these results, the effect of ice on the normal force is observed mostly at the angle of attack near stall, where there is a reduction in the maximum normal force for all flap settings. This effect is most pronounced with the flaps setting of $\delta_{f}=20$. The reduced normal force is similar to findings with twodimensional airfoil research, but note that the stall break and post-stall character is similar to the No-Ice baseline. This small change is due to the rather benign stall characteristics of the Twin Otter wing and the size and shape of the wing ice tested. 


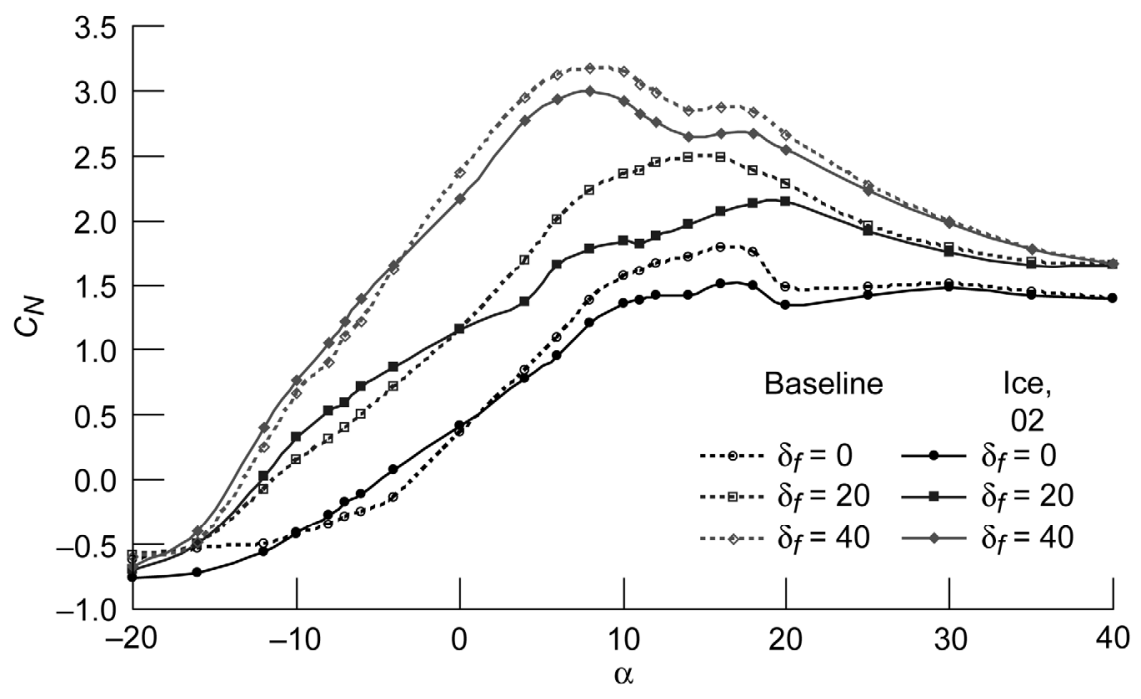

Figure 15.-Twin Otter normal force coefficient for various flap settings with No-Ice baseline and ICE02 configurations.

\section{b. Pitching Moment}

As with the normal force, the pitching moment coefficient data were measured over a wide range of angles of attack, sideslip angles, elevator deflections, rotational velocities, and pitch rates during forced oscillations. Data from these measurements were tabularized into five databases so that the pitching moment coefficent can be represented by. Similar to the $C_{N}$ equations, there is a corolary equation and set of lookup tables for the ICE02 configuration. There is an additional term in the $C_{m}$ equation for the thrust effects $-\Delta C_{m_{\mathrm{CT}}}$. This database was developed using existing NASA Twin Otter flight data.

Pitching moment coefficient model for No-Ice baseline.

$$
\begin{aligned}
C_{m_{\mathrm{TOTAL} \text { CLEAN }}} & =C_{m_{\mathrm{BASII}}}\left(\alpha, \beta, \delta_{f}\right)+\Delta C_{m \mathrm{ROT}}\left(\alpha, \Omega b / 2 V * \operatorname{SGN}(\beta),|\beta|, \delta_{f}\right)+\Delta C_{m_{\mathrm{DE}}}\left(\alpha, \delta_{e}, \delta_{f}\right) \\
& +\Delta C_{m_{Q}}\left(\alpha, q \bar{c} / 2 V, \delta_{f}\right)+\Delta C_{m_{\mathrm{CT}}}\left(\alpha, \mathrm{C}_{\mathrm{T}}, \delta_{f}\right)
\end{aligned}
$$

As an example of the $C_{m_{\text {BASIC }}}$ databases, the pitching moment coefficient data for the Twin Otter with flaps at $0^{\circ}, 20^{\circ}$, and $40^{\circ}$ are presented in figure 16 for the No-Ice baseline and the ICE02 configurations. The effect that ice has is influenced by the flap deflection, $\delta_{f}$. With $\delta_{f}=0^{\circ}$, there is a general positive shift in $C_{m}$ for $A o A>-7^{\circ}$, indicating the download from the horizontal tail is reduced for the given elevator deflection. Also, the static longitudinal stability $\left(C_{m \alpha}\right)$ is reduced significantly for $A o A<-7^{\circ}$, indicating longitudinal instability at this range. With $\delta_{f}=20$ and $40^{\circ}$, the differences caused by the ice are insignificant in the linear range, but reduced static longitudinal stability occurs for $A o A>8^{\circ}$ and for $A o A<-4^{\circ}$. The wing ice causes the reduced $C_{m \alpha}$ at positive $A o A$, whereas the ice on the horizontal tail reduced the $C_{m \alpha}$ at the negative $A o A$.

To illustrate the data in the $\Delta C_{m_{\mathrm{DE}}}$ lookup tables, figure 17 is provided. Overall, the elevator is effective in creating proper pitching moments throughout the $A o A$ range with or without ice. However, the ice does reduce the amount of pitching moment effected by the elevator in the $-10<A o A<10^{\circ}$ range. This means that larger elevator deflections are required to trim the iced aircraft. One thing to note is this effect is more pronounced with greater flap deflections. As flaps are deflected, the inflow angles at the horizontal tail increase, causing separation bubbles to extend and reducing the effectiveness of the elevator. As seen in figure 18, the effect of the ice is greater in the $\delta_{f}=40$ case and extends to lower angles of attack than when the flaps are not deflected. 


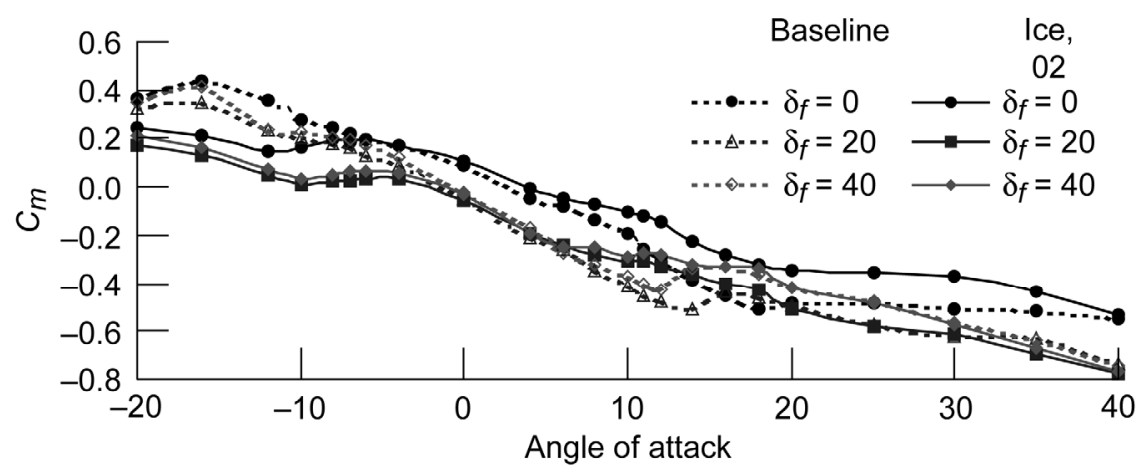

Figure 16.-Twin Otter pitching moment coefficient for various flap settings with No-Ice baseline and ICE02 configurations.

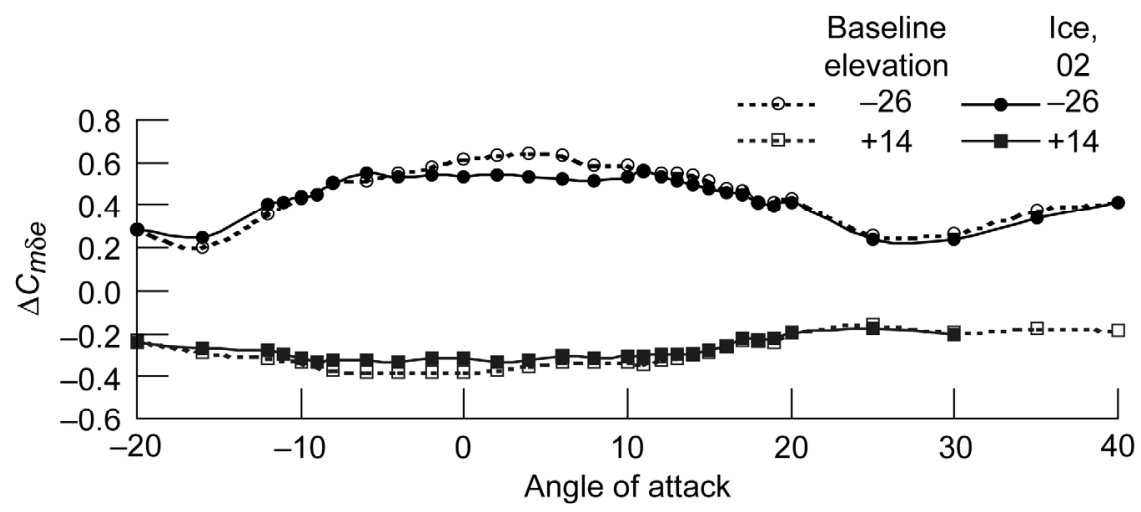

Figure 17.-Twin Otter pitching moment coefficient increment for No-Ice baseline and ICE02 due to elevator deflection $\left(\delta_{f}=0\right)$.

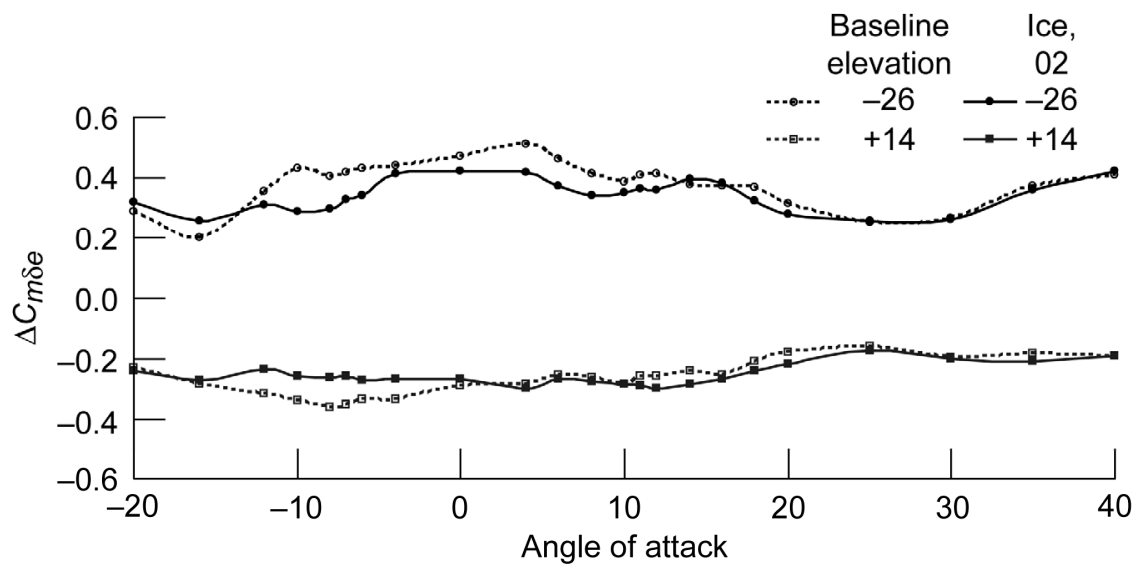

Figure 18.-Twin Otter pitching moment coefficient increment for No-Ice baseline and ICE02 due to elevator deflection $\left(\delta_{f}=40\right)$. 


\section{c. Model Equations for Remaining Force and Moments}

For completeness, the remaining force and moment equation models for the No-Ice Baseline Twin Otter are shown below in equations (4) to (7). Like the normal force and pitching moments, each of these equations has identical model structure for the iced case, but different values within the lookup tables.

Axial force coefficient model for No-Ice baseline.

$$
C_{A_{\mathrm{TOTAL} C \mathrm{TEAN}}}=C_{A_{\mathrm{BASIC}}}\left(\alpha, \beta, \delta_{f}\right)+\Delta C_{A_{D E}}\left(\alpha, \delta_{e}, \delta_{f}\right)+\Delta C_{\mathrm{AQ}}\left(\alpha, q \bar{c} / 2 V, \delta_{f}\right)+\Delta C_{\mathrm{ACT}}\left(\alpha, \mathrm{CT}, \delta_{f}\right)
$$

Side force coefficient model for No-Ice baseline.

$$
\begin{aligned}
C_{Y_{\text {TOTAL CLEAN }}} & =C_{Y_{\mathrm{BASIC}}}\left(\alpha, \beta, \delta_{f}\right)+\Delta C_{Y_{\mathrm{ROT}}}\left(\alpha, \Omega b / 2 \mathrm{~V} * \operatorname{SGN}(\beta),|\beta|, \delta_{f}\right) * \operatorname{SGN}(\beta) \\
& +\Delta C_{Y_{\mathrm{DA}}}\left(\alpha,\left|\delta_{a}\right|, \delta_{f}\right) * \operatorname{SGN}\left(\delta_{a}\right)+\Delta C_{Y_{\mathrm{DR}}}\left(\alpha,\left|\delta_{r}\right|\right) * \operatorname{SGN}\left(\delta_{\mathrm{r}}\right) \\
& +\Delta C_{Y_{\mathrm{P}}}\left(\alpha, p b / 2 \mathrm{~V}, \delta_{f}\right)+\Delta C_{Y_{r}}\left(\alpha, r b / 2 \mathrm{~V}, \delta_{f}\right)
\end{aligned}
$$

Rolling moment coefficient model for No-Ice baseline.

$$
\begin{aligned}
C_{l_{\mathrm{TOTAL} C L \mathrm{CLN}}} & =C_{I_{\mathrm{BASIC}}}\left(\alpha, \beta, \delta_{f}\right)+\Delta C_{I_{\mathrm{ROT}}}\left(\alpha, \Omega b / 2 V * \operatorname{SGN}(\beta),|\beta|, \delta_{f}\right) * \operatorname{SGN}(\beta)+\Delta C_{I_{\mathrm{DA}}}\left(\alpha, \delta_{a}, \delta_{f}\right) \\
& +\Delta C_{I_{D R}}\left(\alpha, \delta_{r}, \delta_{f}\right)+\Delta C_{I_{P}}\left(\alpha, p b / 2 V, \delta_{f}\right)+\Delta C_{I_{r}}\left(\alpha, r b / 2 V, \delta_{f}\right)
\end{aligned}
$$

Yawing moment coefficient model for No-Ice baseline.

$$
\begin{aligned}
C_{n_{\mathrm{TOTALCLEAN}}} & =C_{n_{\mathrm{BASIC}}}\left(\alpha, \beta, \delta_{f}\right)+\Delta C_{n_{\mathrm{ROT}}}\left(\alpha, \Omega b / 2 \mathrm{~V} * \operatorname{SGN}(\beta),|\beta|, \delta_{f}\right) * \operatorname{SGN}(\beta) \\
& +\Delta C_{n_{\mathrm{DA}}}\left(\alpha,\left|\delta_{a}\right|, \delta_{f}\right) * \operatorname{SGN}\left(\delta_{a}\right)+\Delta C_{n_{\mathrm{DR}}}\left(\alpha,\left|\delta_{r}\right|, \delta_{f}\right) * \operatorname{SGN}\left(\delta_{r}\right) \\
& +\Delta C_{n_{\mathrm{IP}}}\left(\alpha, p b / 2 \mathrm{~V}, \delta_{f}\right)+\Delta C_{n_{r}}\left(\alpha, r b / 2 \mathrm{~V}, \delta_{f}\right)
\end{aligned}
$$

\section{Simulating Icing Effects}

\section{A. Implementing Flight Simulation Models}

For the purposes of the research to understand the icing effects on flight dynamics, the flight models described above were implemented using D-Six, (Bihrle Applied Research, Inc.) a commercial off-theshelf product from Bihrle Applied Research, Inc. D-Six is a PC-based simulation environment that fully supported both the Twin Otter and Cessna business jet simulation models development, as well as the analysis and validation activities.

One key objective of these research efforts was to enable real-time, "pilot-in-the-loop" simulations to demonstrate icing effects on flight dynamics to pilots and engineers. D-Six provided the simulation environment to accomplish this because it permits the dynamic linking of other object modules that can control everything from the simulation integration scheme to external graphics and network communications with no requirement to edit the source code. Pilot in the loop simulations will be further discussed in the "Utilizing Simulation Models" subsection. 


\section{B. Validating Flight Simulation Models}

New flight test data were required to validate the flight simulation models. For the Twin Otter, a flight test program was conducted with the No-Ice baseline, artificial ice on the horizontal tail only (ICE01 configuration), and artificial ice on the wing, horizontal tail and vertical tail (ICE02 configuration) (ref. 23). Flight test maneuvers included control doublets, idle-power stalls, steady-heading sideslips, thrust transitions, throttle sweep, wind up turns, and simulated approach and missed approach.

Flight data from these maneuvers were then imported into D-Six for analysis and validation of the simulation models. A validation tool called "Overdrive" enabled the validation of the simulation aerodynamic database against flight-extracted data using the process illustrated in figure 19. At each time slice, Overdrive extracts aerodynamic moment coefficients from the flight-recorded time histories, as shown on the right side of figure 19. Angular rates are numerically differentiated to obtain the angular acceleration of the vehicle. After the removal of the inertial effects, the remainder is nondimensionalized to generate the aerodynamic force and moment coefficients experienced during flight.

At each time step, flight-recorded states, such as angle of attack, angle of sideslip, control surface positions, etc., are used to exercise the aerodynamic model in accordance with the aerodynamic model specification discussed previously. Each aerodynamic model element (i.e., pitching moment due to elevator, etc.) is stored and summed as prescribed in the aerodynamic model. By over-plotting the model predicted coefficients with the flight-extracted total coefficients (fig. 20), differences can be easily identified. Correlating the discrepancies with the excitation of the individual elements and parameters from the flight time history aids to isolate potential weaknesses in the aerodynamic model.

Overdrive was used with the Twin Otter flight data to validate the models. The validation effort was reported on (ref. 24), but is currently not published.

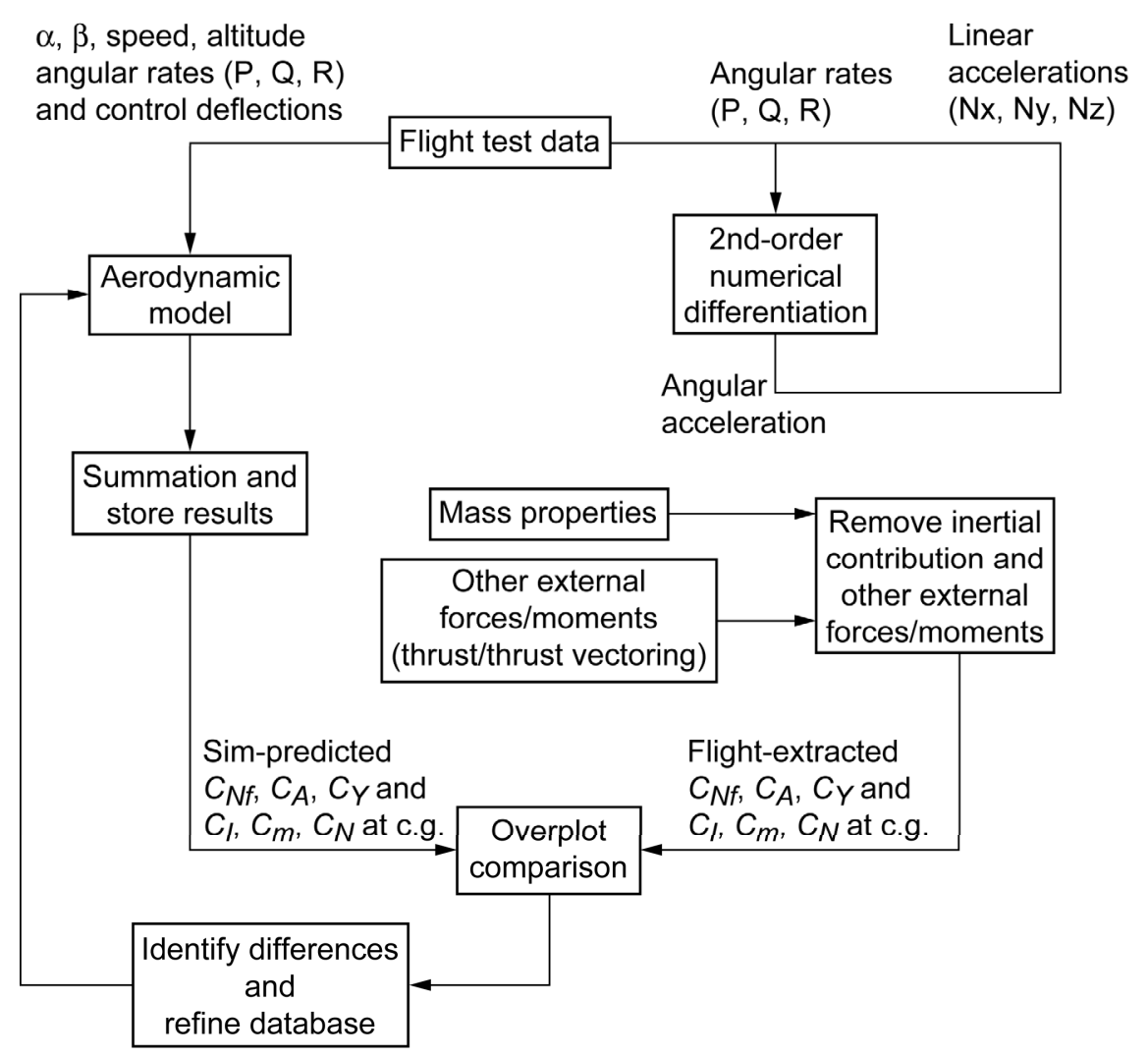

Figure 19.-Overdrive process diagram. 

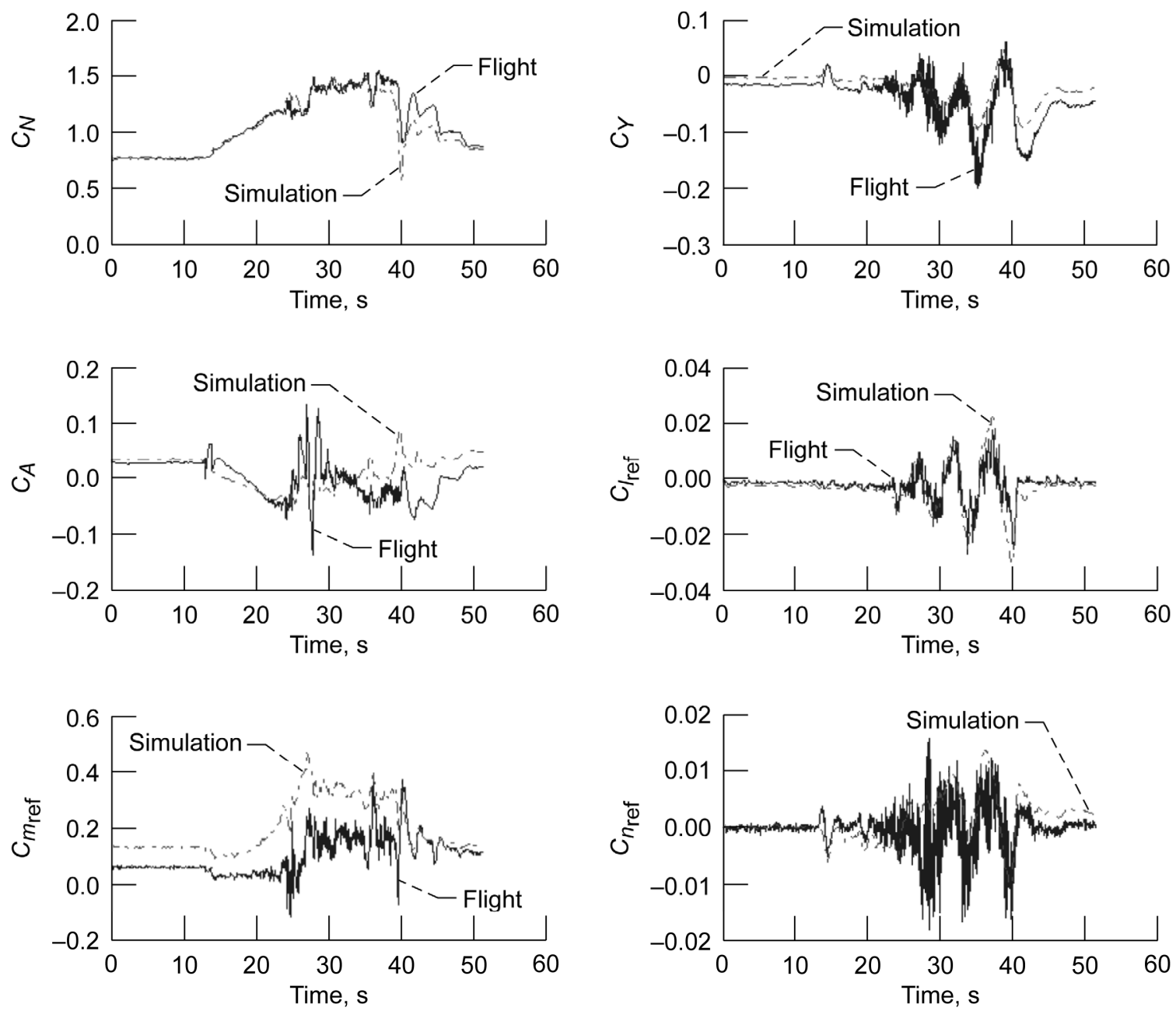

Figure 20.—Sample overdrive result from Twin Otter wing stall maneuver, $\delta_{f}=0$, all iced.

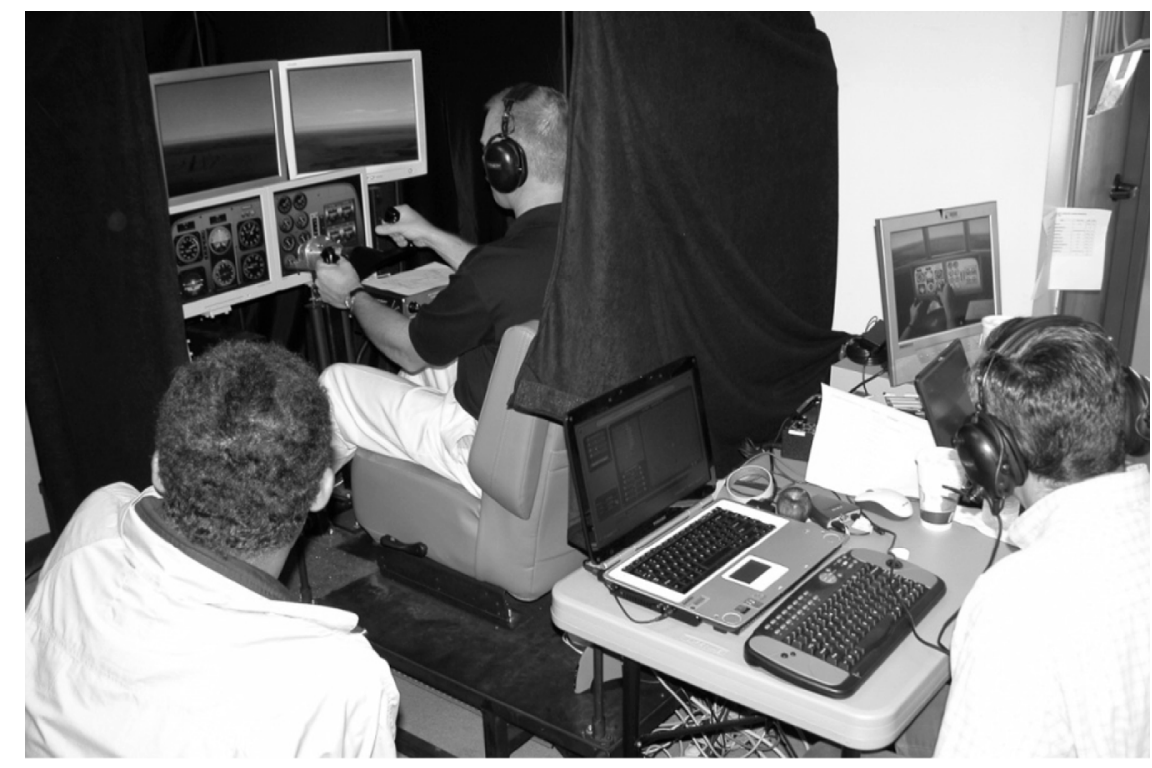

Figure 21.—ICEFTD utilized for pilot education and training. 


\section{Utilizing Flight Simulation Models}

One key objective of these research efforts was to enable real-time, "pilot-in-the-loop" simulations to demonstrate icing effects on flight dynamics to pilots and engineers. Although the simulation models could be run on a laptop or desk-top PC, a portable flight training device called the Ice Contamination Effects Flight Training Device [ICEFTD] (fig. 21) was developed to be a more effective tool (ref. 25).

The ICEFTD consists of a raised platform and framework that supports a pilot seat, a control yoke, rudder pedals, a twin turbo-prop throttle quadrant, a flap selector, three flat-panel monitors for out-thewindow graphics, and two additional flat-panel monitors for instrument panel graphics. The control column is connected to a programmable loader for longitudinal force feedback, whereas the yoke (lateral) and rudder pedals force gradients are provided by spring resistance. Two PCs using D-Six host the simulation models and control the graphics. A third PC, the control loading computer (CLC), controls the electro-mechanical loader to simulate representative column forces. These PCs are mounted under the "floor" of the device and the control loader device is mounted to the frame forward of the pilot's feet. A curtain surrounds the ICEFTD to isolate the pilot from external visual distractions. All of the electrical components are connected through a daisy-chained series of electrical power strips/surge protectors so that only a single $110 \mathrm{~V}$ wall socket is needed to power the entire device. The platform is $33.5 \mathrm{in}$. wide by $84 \mathrm{in}$. long, and weighs $450 \mathrm{lb}$. It has 4 caster wheels for easy transportation and screw down feet to lock down for demonstrations. This design is well-suited for mobility and usability at various settings-from labs or offices to class rooms or hangars.

Both the Twin Otter and Cessna business jet flight models have been implemented on the ICEFTD and were used for pilot education and training as well as pilot evaluations of the simulation models. The ICEFTD has been used to demonstrate icing effects on Twin Otter flight dynamics to over 150 pilots at seminars and short courses held by the University of Tennessee Space Institute, National Test Pilot School, Flight Safety International, and several conference exhibits (ref. 26). The ICEFTD was also used in conjunction with the flight model validation flight tests of the Cessna business jet (ref. 27). Simulator sessions were conducted prior to the flight tests to identify anomalous flight characteristics that were predicted by the simulator. After the flight tests and flight model updates based on the new flight records, Cessna flight test pilots re-evaluated the simulation models on the ICEFTD. For both airplane types, pilots could readily see the changes in performance, stall characteristics and the increased workload to recover from the stall with the iced airplane.

\section{Future Directions}

As described above, there can be nearly an infinite number of ice shapes, each having a range of effects on the aerodynamics of individual wings, fuselage, empennage, and other surfaces. More importantly, these infinite number of ice shapes has a wide range of effects on the aerodynamics of the aircraft as an integrated machine-human system. The research with iced two-dimensional airfoils has helped reduce the scope of ice shapes that need to be considered by identifying key ice shape features and the resulting flow fields. Similar research efforts are needed with three-dimensional wings and tails with control surfaces to determine if three-dimensional ice features such as scallops need to be considered as part of the so-called critical ice shapes.

Regarding icing effects on flight dynamics, the research efforts with the Twin Otter and business jet simulation models are a great start in that they have provided a method to develop and validate icing effects simulation models. These flight simulation models and the flight training device are valuable resources for additional research into icing effects on flight dynamics, pilot education, and future flight training simulator requirements. But the knowledge gained through the efforts with the Twin Otter and business jet cannot be applied across the entire spectrum of aircraft. Further efforts are needed to identify icing effects on other classes of aircraft, such as regional jets, large transports, and future designs such as blended wing body. 
Understanding these needs, NASA is currently utilizing the Twin Otter flight simulation models to develop and test new methods for identifying icing effects in real-time to provide envelope protection to avoid loss of control. This effort is being conducted through a NASA Research Announcement (NRA) with the University of Tennessee Space Institute and Bihrle Applied Research, Inc.

NASA is also initiating a new icing effects simulation activity using the NASA Langley Generic Transport Model (GTM). A significant database has already been developed using a generic twin-engine large transport model configuration to develop recovery strategies from loss of control events. To date, the emphasis of the effort has been on damaged aircraft or failure conditions, such as a rudder hard-over. The new icing effects effort will provide another scenario under which loss of control can occur. Flight simulation models will be developed from this database and used in conjunction with adaptive control methods development and testing.

\section{Summary}

The general effects of icing on aerodynamics are increased drag, reduced stall angle of attack and maximum lift, and altered pressure distribution over the airfoil surface. In addition, the stall break and post-stall characteristics can be dramatically different in the iced cases when compared to the No-Ice baseline. These aerodynamic effects have been studied using two-dimensional airfoil sections and much has been learned regarding ice shape features and the associated flow fields that result in these performance degradations.

To understand the integrated effects of icing on aircraft performance, stability and control, research has been conducted using sub-scale complete aircraft models. From this research, flight simulation models were developed that incorporate the nonlinear nature of icing effects on the forces and moments along all three axes. These flight models can be implemented into piloted flight simulators for pilot evaluation and loss of control recovery strategies.

Significant progress has been made in this area of icing flight dynamics research, but the knowledge gained with the limited number of models may not be applicable to other airplane configurations. Additional research efforts using other airplane models are needed to extend our current understanding of icing flight dynamics.

\section{References}

1. National Transportation Safety Board, Factual Report on Cessna CE-208 Caravan Accident on October 21, 2001 at Dillingham, Alaska, NTSB ID DCA02MA003.

2. National Transportation Safety Board, Safety Recommendation to Mitigate the Existing Risk to the Cessna 208 Fleet during the Current Icing Season. A-06-01 through 03, January 17, 2006.

3. National Transportation Safety Board, Crash During Approach to Landing, Circuit City Stores, Inc., Cessna Citation 560, N500AT, Pueblo, Colorado, February 16, 2005, Aircraft Accident Report NTSB/AAR-07/02. Washington, DC., January 2007.

4. National Transportation Safety Board, Safety Recommendation on High-Altitude, Dual-Engine Flameouts on Raytheon Beechjet 400 Series Airplanes Powered by Pratt \& Whitney Canada, JT15D5 Turbofan Engines, A-06-56/59, Aug. 2006.

5. National Transportation Safety Board, In-Flight Icing Encounter and Loss of Control, Simmons Airlines, D.B.A. American Eagle Flight 4184 Avions De Transport Regional (ATR) Model 72-212, N401am Roselawn, Indiana October 31,1994, NTSB Aircraft Accident Report, NTSB/AAR-96/01, Washington, DC., July 1996.

6. National Transportation Safety Board, In-Flight Icing Encounter And Uncontrolled Collision With Terrain; Comair Flight 3272; Embraer Emb-120rt, N265ca; Monroe, Michigan, January 9, 1997, NTSB Aircraft Accident Report, NTSB/AAR-98/04, Washington D.C., November 1998.

7. Saab-SF340A, VH-LPI, Eildon Weir, Victoria on 11 November 1998, Australian Transport Safety Bureau AIR SAFETY INVESTIGATION 199805068, April 2001. 
8. Aviation Safety Council, GE791 Occurrence Investigation Report, In-Flight Icing Encounter and Crash into the Sea Transasia Airways Flight 791, ATR72-200, B-22708, 17 Kilometers Southwest of Makung City, Penghu Islands, Taiwan, December 21, 2002, ASC-AOR-05-04-001, Taipei, Taiwan.

9. Inflight Loss of Control due to Airframe Icing Saab 340B, VH-OLM, 28 June 2002, Australian Transport Safety Bureau AIR SAFETY INVESTIGATION BO/2002030704, December 2003.

10. National Transportation Safety Board, Safety Recommendation to Mitigate the Existing Risk to the Saab 340 Fleet When Operating in Icing Conditions. A-06-48/51, July 10, 2006.

11. "Roll Oscillations on Landing, Air Canada, Airbus 321-211, C-GJVX and C-CIUF, Toronto/Lester B. Pearson International Airport, Ontario, 07 December 2002," Transportation Safety Board of Canada Aviation Investigation Report A02O0406.

12. Russell, P., Pardee, J., "Joint Safety Analysis Team-CAST Approved Final Report Loss of Control JSAT Results and Analysis," December 2000.

13. Bragg, M., Broeren, A., Addy, H., Potapczuk, M., Guffond, D., Montreuil, E., "Airfoil Ice-Accretion Aerodynamics Simulation," AIAA Paper 2007-085, Jan. 2007.

14. “Aircraft Ice Protection,” Advisory Circular AC No 20-73A, Aug. 2006.

15. Bragg, M.B., Broeren, A.P., Blumenthal, L.A., "Iced-Airfoil Aerodynamics," Progress in Aerospace Sciences vol. 41, pp. 323-362, 2005.

16. Johnson, C.L., "Wing Loading, Icing and Associated Aspects of Modern Transport Design," Journal of the Aeronautical Sciences, vol. 8, no. 2. December, 1940.

17. Reehorst, A., Potapczuk, M., Ratvasky, T., Gile-Laflin, B., "Wind Tunnel Measured Effects on a Twin-Engine Short-Haul Transport Caused by Simulated Ice Accretions, Data Report," NASA TM 107419, May 1997.

18. Lee, S., Barnhart, B.P., Ratvasky, T.P., Dickes, E.G., and Thacker, M., "Dynamic Wind-Tunnel Testing of a Sub-Scale Iced Business Jet," AIAA Paper 2006-0261.

19. Papadakis, M., Gile Laflin, B.E., Youssef, G.M., and Ratvasky, T.P., “Aerodynamic Scaling Experiments With Simulated Ice Accretions," AIAA Paper 2001-0833.

20. Lee, S., Ratvasky, T.P., Thacker, M., and Barnhart, B.P., "Geometry and Reynolds-Number Scaling on an Iced Business-Jet Wing," AIAA Paper 2005-1066, NASA/TM-2005-213575, Aug. 2005.

21. Gringas, D.R., Dickes, E.G., Ratvasky, T.P., and Barnhart, B.P., "Modeling of In-Flight Icing Effects for Pilot Training," AIAA Paper 2002-4605.

22. Barnhart, B.P., Dickes, E.G., Gingras, D.R., Ratvasky, T.P., "Simulation Model Development for Icing Effects Flight Training," NASA/TM-2003-212115, SAE-2002-01-1527, April 2003.

23. Ratvasky, T.P., Blankenship, K., Rieke, W., Brinker, D.J., "Iced Aircraft Flight Data for Flight Simulator Validation,” NASA/TM-2003-212114, SAE-2002-01-1528, April 2003.

24. Barnhart, B.P., "An Icing Effects Flight Training Simulator Aerodynamic Model Development," NASA CR (to be published).

25. Ratvasky, T.P., Ranaudo, R.J., Barnhart, B.P., Dickes, E.G., Gingras, D.R., "Development and Utility of a Piloted Flight Simulator for Icing Effects Training," NASA/TM-2003-212116, AIAA-20030022, April 2003.

26. Ratvasky, T.P., Ranaudo, R.J., Blankenship, K.S., Lee, S., "Demonstration of an Ice Contamination Effects Flight Training Device," NASA/TM-2006-214233, AIAA Paper 2006-0677, May 2006.

27. Ratvasky, T.P., Barnhart, B.P., Lee, S., Cooper, J., "Flight Testing an Iced Business Jet for Flight Simulation Model Validation," NASA/TM-2007-214936, AIAA Paper 2007-0089, December 2007. 


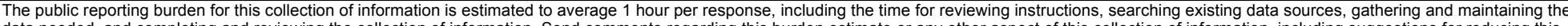

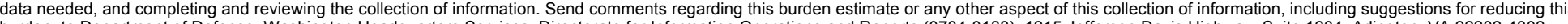

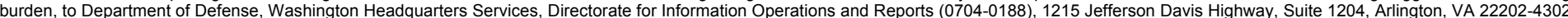

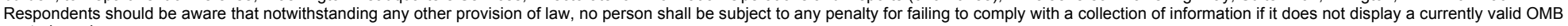
control number.

PLEASE DO NOT RETURN YOUR FORM TO THE ABOVE ADDRESS.

\section{REPORT DATE (DD-MM-YYYY) \\ 2. REPORT TYPE \\ 3. DATES COVERED (From - To)}

01-12-2008

\section{TITLE AND SUBTITLE}

Current Methods for Modeling and Simulating Icing Effects on Aircraft Performance,

Stability and Control

5a. CONTRACT NUMBER

5b. GRANT NUMBER

5c. PROGRAM ELEMENT NUMBER

6. AUTHOR(S)

Ratvasky, Thomas, P.; Barnhart, Billy, P.; Lee, Sam

\section{5d. PROJECT NUMBER}

5e. TASK NUMBER

5f. WORK UNIT NUMBER

WBS 457280.02.07.03.02

\section{PERFORMING ORGANIZATION \\ REPORT NUMBER}

E-16643

National Aeronautics and Space Administration

John H. Glenn Research Center at Lewis Field

Cleveland, Ohio 44135-3191

\section{SPONSORING/MONITORING AGENCY NAME(S) AND ADDRESS(ES)}

National Aeronautics and Space Administration

Washington, DC 20546-0001

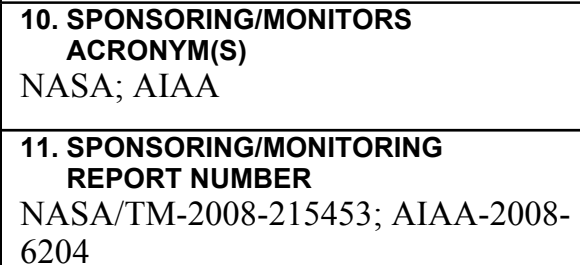

\section{DISTRIBUTION/AVAILABILITY STATEMENT}

Unclassified-Unlimited

Subject Categories: 05 and 08

Available electronically at http://gltrs.grc.nasa.gov

This publication is available from the NASA Center for AeroSpace Information, 301-621-0390

\section{SUPPLEMENTARY NOTES}

\section{ABSTRACT}

Icing alters the shape and surface characteristics of aircraft components, which results in altered aerodynamic forces and moments caused by air flow over those iced components. The typical effects of icing are increased drag, reduced stall angle of attack, and reduced maximum lift. In addition to the performance changes, icing can also affect control surface effectiveness, hinge moments, and damping. These effects result in altered aircraft stability and control and flying qualities. Over the past 80 years, methods have been developed to understand how icing affects performance, stability and control. Emphasis has been on wind tunnel testing of two-dimensional subscale airfoils with various ice shapes to understand their effect on the flow field and ultimately the aerodynamics. This research has led to wind tunnel testing of subscale complete aircraft models to identify the integrated effects of icing on the aircraft system in terms of performance, stability, and control. Data sets of this nature enable pilot in the loop simulations to be performed for pilot training, or engineering evaluation of system failure impacts or control system design.

\section{SUBJECT TERMS}

Aircraft icing; Flight simulation; Flight simulators; Flight safety

\section{SECURITY CLASSIFICATION OF:}

\section{a. REPORT}

$\mathrm{U}$

\section{b. ABSTRACT} $\mathrm{U}$

\section{LIMITATION OF} ABSTRACT

UU

18. NUMBER
OF
PAGES
27

PAGE

$\mathrm{U}$ 19a. NAME OF RESPONSIBLE PERSON

STI Help Desk (email:help@sti.nasa.gov)

19b. TELEPHONE NUMBER (include area code) 301-621-0390 

